\title{
Arctic charr brain transcriptome strongly affected by summer seasonal growth but only subtly by feed deprivation
}

\author{
Anja Striberny ${ }^{1 *} \mathbb{D}$, Even H. Jørgensen ${ }^{1}$, Christophe Klopp ${ }^{2}$ and Elodie Magnanou ${ }^{3}$
}

\begin{abstract}
Background: The Arctic charr (Salvelinus alpinus) has a highly seasonal feeding cycle that comprises long periods of voluntary fasting and a short but intense feeding period during summer. Therefore, the charr represents an interesting species for studying appetite-regulating mechanisms in fish.

Results: In this study, we compared the brain transcriptomes of fed and feed deprived charr over a 4 weeks trial during their summer feeding season. Despite prominent differences in body condition between fed and feed deprived charr at the end of the trial, feed deprivation affected the brain transcriptome only slightly. In contrast, the transcriptome differed markedly over time in both fed and feed deprived charr, indicating strong shifts in basic cell metabolic processes possibly due to season, growth, temperature, or combinations thereof. The GO enrichment analysis revealed that many biological processes appeared to change in the same direction in both fed and feed deprived fish. In the feed deprived charr processes linked to oxygen transport and apoptosis were down- and up-regulated, respectively. Known genes encoding for appetite regulators did not respond to feed deprivation. Gene expression of Deiodinase 2 (D/O2), an enzyme implicated in the regulation of seasonal processes in mammals, was lower in response to season and feed deprivation. We further found a higher expression of VGF (non-acronymic) in the feed deprived than in the fed fish. This gene encodes for a neuropeptide associated with the control of energy metabolism in mammals, and has not been studied in relation to regulation of appetite and energy homeostasis in fish.

Conclusions: In the Arctic charr, external and endogenous seasonal factors for example the increase in temperature and their circannual growth cycle, respectively, evoke much stronger responses in the brain than 4 weeks feed deprivation. The absence of a central hunger response in feed deprived charr give support for a strong resilience to the lack of food in this high Arctic species. DIO2 and VGF may play a role in the regulation of energy homeostasis and need to be further studied in seasonal fish.
\end{abstract}

Keywords: Feed deprivation, Salvelinus alpinus, RNA-seq, Brain transcriptome, Neuropeptides, Season

\section{Background}

Feeding is pivotal for animals in order to sustain their energy and substrate needs to live, grow and reproduce. In mammals, energy intake and expenditure are tightly regulated by a crosstalk of peripheral and central signalling actors and pathways [1]. Peripherally derived hunger (orexigenic) and satiety (anorexigenic) signals as well as long-term signals reporting energy status are perceived

\footnotetext{
* Correspondence: anja.striberny@uit.no

'Department of Arctic and Marine Biology, UiT - The Arctic University of Norway, Tromsø, Norway

Full list of author information is available at the end of the article
}

and processed in a number of brain nuclei in order to control short-term (meal-to-meal) appetite and long-term energy homeostasis $[2,3]$. Of these, the arcuate nucleus (ARC) in the hypothalamus represents the pivot for controlling food intake and energy balance [4]. The ARC contains two populations of "first order" neurons, one expressing the anorexigenic proopiomelanocortin (POMC) and cocaine-and amphetamine regulated transcript (CART), the other the orexigenic agouti-related peptide (AgRP) and neuropeptide Y (NPY) [3]. These project to "second order" neurons that transduce orexigenic and anorexigenic signals via NPY and melanocortin receptors 
(MCR) [1]. While NPY signalling through its receptors causes an orexigenic response, signalling through MCRs results in either an anorexigenic or an orexigenic response. POMC-derived $\alpha$-melanocyte-stimulating hormone $(\alpha-\mathrm{MSH})$ is a melanocortin 4 receptor (MC4R) agonist and a potent appetite suppressor in mammals [5]. $\mathrm{AgRP}$, on the other hand, is an inverse agonist to the constitutively active MCRs and increases food intake [6]. These appetite and energy signalling neuropeptides have been shown to be evolutionary conserved $[7,8]$ and to be involved in the control of food intake in fish $[9,10]$. However, responses of central appetite regulators to energy perturbation vary across species and even within species depending on the experimental design [11]. For example, $N P Y$ expression is higher after 7 days of feed deprivation in the hypothalamus of zebrafish (Danio rerio) [12] and in the preoptic area of chinook salmon (Oncorhynchus tshawytscha) and coho salmon (Oncorhynchus kisutch) [13], whereas in cunner (Tautogolabrus adsperus), hypothalamic $N P Y$ expression remains unaffected after 7 days feed deprivation [14]. Such differences in the response to feed deprivation are not unexpected as fish represent the most diverse group of vertebrates with a myriad of adaptations to spatially different and temporal changing environments. For example, in the high-latitude inhabiting anadromous (sea-migrating) Arctic charr (Salvelinus alpinus), food intake varies dramatically from little or no feeding while residing in fresh water during winter to voracious feeding during their short summer residence in the sea $[15,16]$. This behaviour, which presumably developed as a response to seasonal and spatial differences in water temperature and food availability at high latitudes, now appears to be regulated independently of these factors; captive offspring of anadromous Arctic charr exhibit pronounced seasonal changes in appetite and growth when held at constant temperature and given food in excess [17]. Despite such seasonal changes in food intake, the expressions of orexigenic and anorexigenic appetite regulators in different brain regions is similar between anorexic winter charr with hyperphagic summer charr [18]. Furthermore, the expressions of orexigenic and anorexigenic neuropeptides in the hypothalamus are unaffected by short- and long-term feed deprivation in this species [19]. However, in these and in most other studies investigating appetite regulation in fish, expression levels of known appetite regulators have been measured by RT-qPCR, a method with the drawback of restricting the focus to a limited number of genes. The fact that novel actors in the complex control of food intake are still being discovered calls for a more global approach when investigating appetite regulation in fish. Today, high-throughput RNA sequencing is a powerful tool in experimental biology. Transcriptomic approaches have been applied in various contexts to improve knowledge of the biology of the seasonal Arctic charr [20, 21], albeit not with focus on appetite regulation. Consequently, we sequenced the brain transcriptome of fed and feed deprived charr during their natural summertime growth in an attempt to advance the knowledge on global responses to feed deprivation, assess alterations of known central appetite regulators, and to identify possible new actors involved in the control of appetite and energy metabolism in fish.

\section{Results \\ Morphometrics}

The experiment was performed on two-year old immature anadromous Arctic charr held under natural photoperiod ( $24 \mathrm{~h}$ light at that time of the year) and ambient water temperature. Growth development during the 4 weeks experimental period was assessed on subsamples of 15 tagged fish per treatment group. Average body mass and condition factor were $98.0 \pm 4.2 \mathrm{~g}$ and $1.04 \pm$ 0.02 on June 25,2014 , the start of the experiment $\left(\mathrm{T}_{0}\right)$ (Fig. 1). On July 23, the end of the experiment $\left(\mathrm{T}_{1}\right)$, body mass and condition factor were markedly higher in fed (Fed) than in feed deprived (FDP) charr with 161.4 \pm 4.7 $g$ and $1.27 \pm 0.01$, and $84.4 \pm 5.2 \mathrm{~g}$ and $0.86 \pm 0.02$ in the fed and FDP charr, respectively. Average body mass and condition factor of the 5 fish sampled for transcriptomics fell in the same range as for the tagged fish and were $108.3 \pm 10.2 \mathrm{~g}$ and $1.05 \pm 0.03$ at $\mathrm{T}_{0}$ and $157.2 \pm 8.3$ $\mathrm{g}$ and $1.25 \pm 0.03$ (Fed) and $80.6 \pm 6.3 \mathrm{~g}$ and $0.92 \pm 0.04$ (FDP) at $\mathrm{T}_{1}$.

\section{De novo transcriptome assembly and annotation}

The de novo brain transcriptome assembly produced 49829 contigs with a FPKM greater than 1 for at least one of the 15 samples. Their total length equalled 84028148 base pairs. The N50 (i.e., the contig length that produces half the bases of the assembly) reached $2663 \mathrm{bp}$ (Table 1).

The annotation rate reached $85.07 \%$ of the 49829 contigs. The Atlantic salmon (Salmo salar) contributed most to the annotation of the Arctic charr brain transcriptome with $57.6 \%$ of the contigs annotated on this species (Fig. 2). All other species contributing to the annotation, except Homo sapiens, were exclusively teleosts including another salmonid, the rainbow trout (Oncorhynchus mykiss). One or more GO identifier could be assigned to 13231 out of the 49829 contigs. Different approaches were used to verify the quality of the contigs. First, the assembly quality and annotation completeness of the transcriptome were assessed by BUSCO analysis. Out of 4584 single-copy ortholog genes common to Actinopterygii, the assembly was $67.2 \%$ complete (2560 complete single-copy BUSCOs and 524 complete duplicated BUSCOs), while only $2.8 \%$ of contigs were fragmented (130 BUSCOs) and 30.0\% were missing (1370 BUSCOs). Second, a comparison to a phylogenetically 

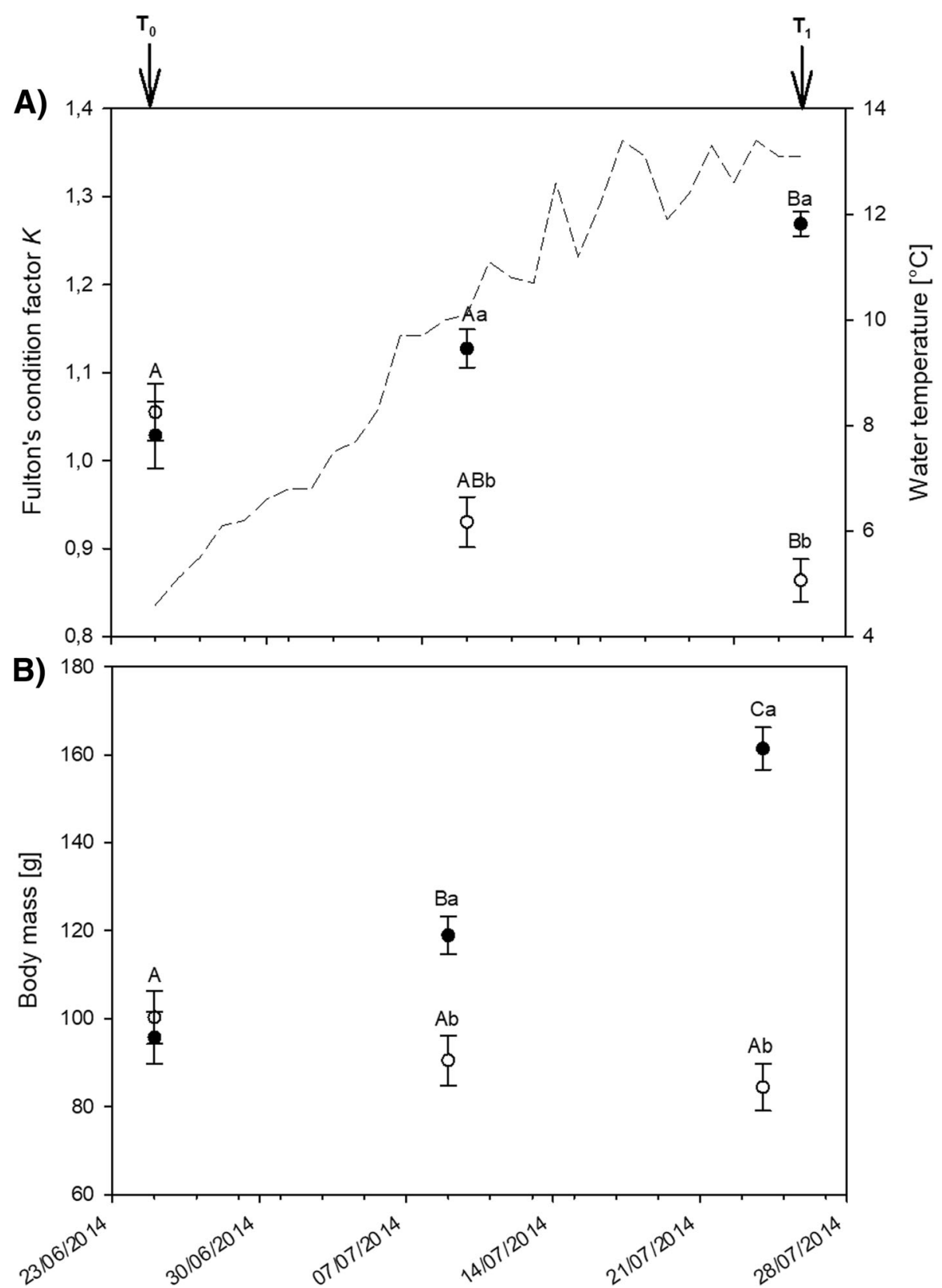

Fig. 1 Fulton's condition factor (a) and body mass (b) of tattooed fed (black dots) and feed deprived Arctic charr (white dots) during the experiment. Charr sampled at $T_{0}$ were measured before distribution to Tank 1 and Tank 2. Dashed line: water temperature. $n=21$ per treatment group. Values are shown as mean \pm SEM. Different capital and lowercase letters denote differences within treatment group at different time points and differences between treatment groups at the given time point, respectively

close species reference proteome was achieved using the Atlantic salmon database from the NCBI. Out of 97555 Salmo salar proteins, 47419 were aligned with at least $80 \%$ identity over $80 \%$ of their length on our assembly, which corresponded to 12238 Arctic charr contigs. Third, initial reads were mapped to the contigs in order to validate to what extent the contigs reflected the initial information. The contigs had high realignment rates that ranged between 88 and $89 \%$ depending on the sample
(15 libraries). Furthermore, the construction of the RNAseq data set was verified by mapping the reads from an Arctic charr gill transcriptome [22] on our set of contigs. On average, $79.35 \%$ of reads from this gill transcriptome (SRA accession: SRX314607) were aligned to the 15 Arctic charr libraries. Finally, both proteins and RNAs from the $S$. alpinus reference genome (NCBI ID: 12179) [23] were aligned to our set of contigs. Out of 59926 proteins, 49212 (82\%) had a hit on the contigs, 
Table 1 General statistics of contigs generated by RNAseq technology for brain gene expression characterization. Only contigs possessing a FPKM greater than 1 for at least one library were considered for annotation and further expression analysis

\begin{tabular}{ll}
\hline Number of base pairs in reads & 42491174498 \\
Number of reads & 420704698 \\
Number of base pairs in contigs (FPKM> 1) & 84028148 \\
Number of contigs (FPKM> 1) & 49829 \\
N50 & 2663 \\
N90 & 816 \\
Number of putative micro-satellites & 34440 \\
Number of putative SNPs & 420406 \\
Number of contigs including SNP & 39484 \\
\hline
\end{tabular}

31316 of these proteins shared over $80 \%$ similarity and $80 \%$ of coverage with the built contigs. Regarding RNAs from the reference genome, $76 \%$ (51217 out of the 67196) had a hit on our contigs, with 24432 RNAs having over $80 \%$ of similarity and $80 \%$ of coverage with the contigs.

\section{Gene expression patterns and differential gene expression}

In order to inspect the overall expression patterns of the 15 samples, a correlation heatmap based on the raw counts of the 49829 contigs possessing a FPKM greater than 1 for at least one sample was drawn (Fig. 3). This analysis highlighted that all samples from $\mathrm{T}_{0}$ clustered together and were markedly different from samples taken at $T_{1}$. Samples of the fed and feed deprived charr at $\mathrm{T}_{1}$ did not cluster in accordance with the treatment group (Fig. 3).

In fed Arctic charr, 2819 contigs differed over time (Table 2). This corresponded to $5.7 \%$ of all sequenced contigs. Among these, 1534 contigs were up-regulated, while 1285 were down-regulated.

In feed deprived charr, 4570 (9.2\%) contigs differed over time (Table 2). Of these 2616 were up-regulated while 1954 were down-regulated from start to the end of experiment. At $\mathrm{T}_{1}$, only 175 contigs $(0.4 \%$ of all contigs) were found to be differentially expressed between FDP and Fed charr (Table 2), with 68 contigs being upregulated and 107 being down-regulated. Matching the six lists of up- and down regulated contigs from the three comparisons in Up-set graphs enabled us to break down the lists of differentially expressed genes and find the intersection points of all three comparisons (Fig. 4). Over time, 1449 contigs were up-regulated and 825 down-regulated in both FDP and fed charr. Interestingly, at the same time, 1421 contigs were uniquely upregulated in the FDP versus $\mathrm{T}_{0}$ comparison.

In contrast, only 825 contigs were uniquely upregulated in fed charr over time. Similarly, 1058 contigs, were uniquely down-regulated in FDP charr over time, whereas only 337 contigs were uniquely down-regulated contigs in the Fed versus $\mathrm{T}_{0}$ comparison. Chi-square tests of the $2 \times 2$ contingency tables of up- and downregulated genes indicated that there was a correlation of the proportion between uniquely and shared differentially expressed contigs and feeding regime over time (up-

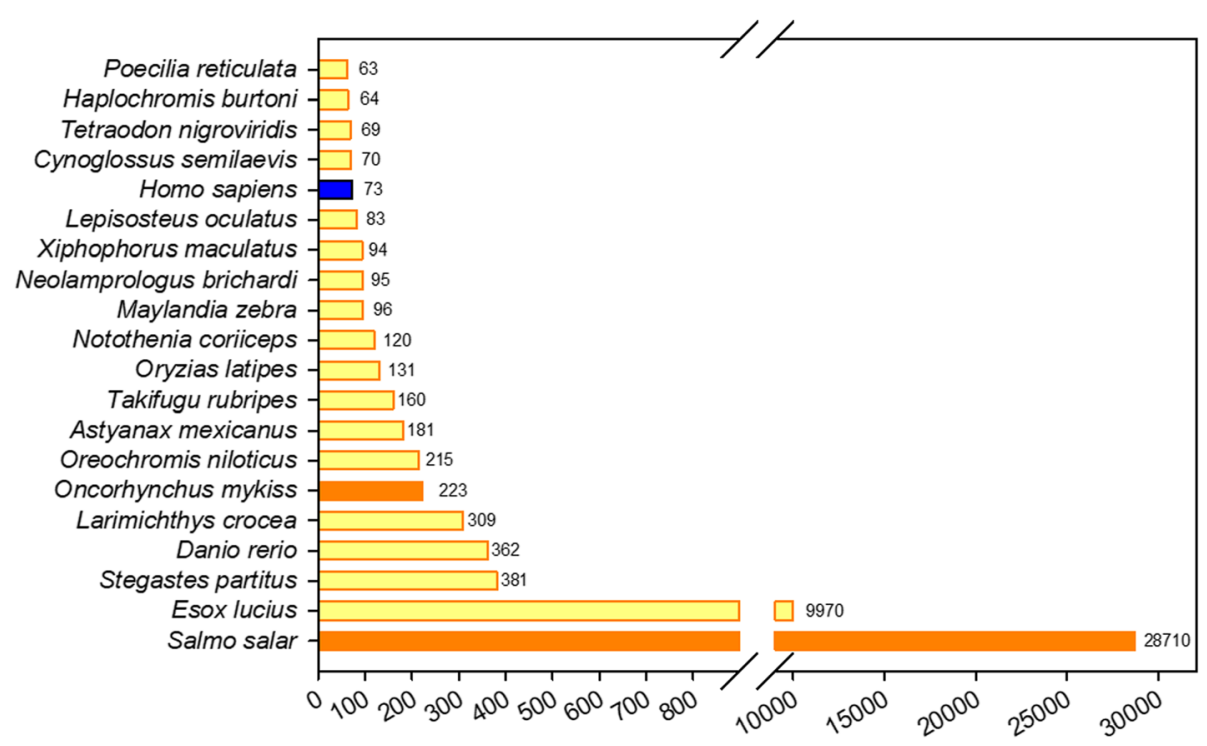

Number of best hits

Fig. 2 Top 20 species contributing the most to best-hit annotations. Best hits were based on all databases involved in the annotation process. Yellow: teleosts, orange: salmonids, blue: mammals 


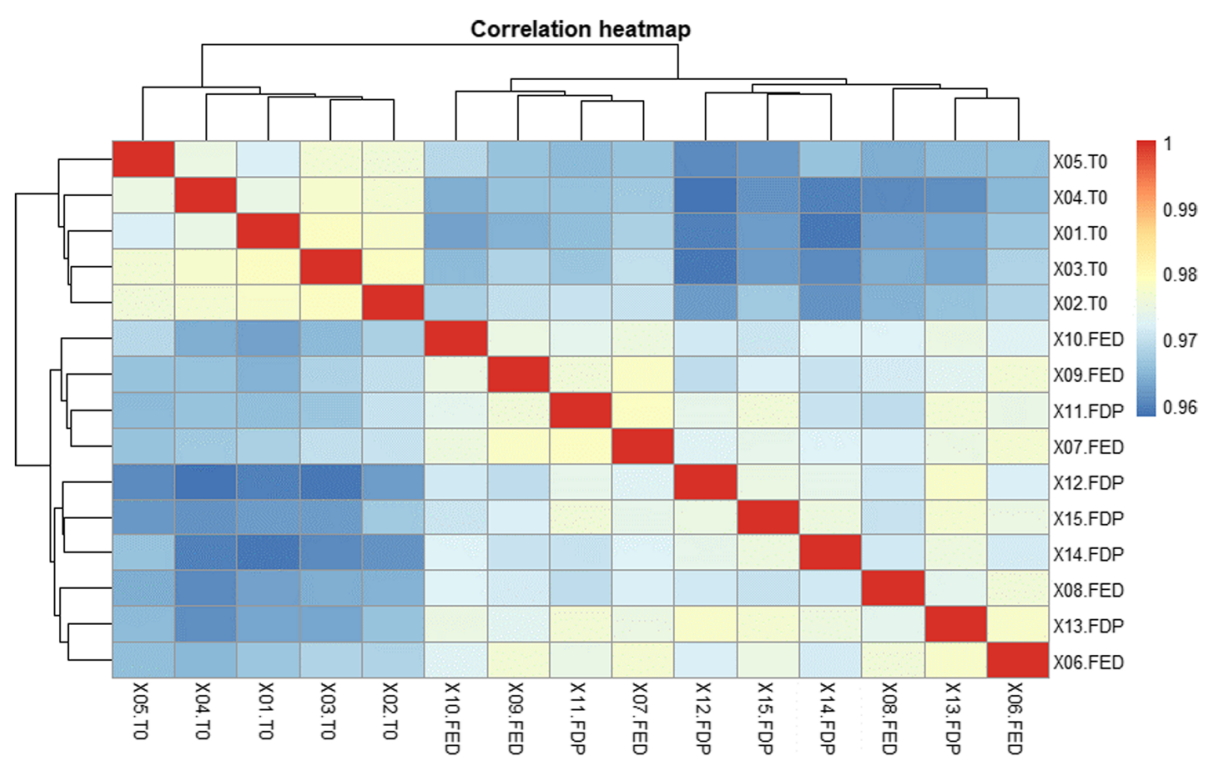

Fig. 3 Correlation heatmap based on raw counts of the 49829 contigs possessing a FPKM greater than 1 for at least one sample. X01-X15: number of sampled fish during the experiment. TO: fish sampled at the start of the experiment (June 25). FED: fed fish sampled at the end of the experiment (July 23). FDP: feed deprived fish sampled at the end of experiment (July 23)

regulated: $\mathrm{X}$-squared $=387.74, \quad p$-value $<0.0001$, downregulated: $X$-squared $=153.5, p$-value $<0.0001$ ) (Fig. 4 ). Only five contigs were up-regulated in the Fed vs $\mathrm{T}_{0}$ comparison whilst down regulated in the FDP versus $\mathrm{T}_{0}$ comparison. No contigs were down-regulated in the Fed vs $\mathrm{T}_{0}$ and at the same time up-regulated in the FDP vs $\mathrm{T}_{0}$ comparison (Fig. 4).

GO enrichment analysis for biological processes (BP) was employed to study the biological functions of the differentially expressed contigs. This would depict global effects of season and feed deprivation during summer on the charr's brain transcriptome.

Contigs that were only up-regulated in fed fish over time were associated with biological processes that included oxygen transport and protein related biological processes (Table 3). Down-regulated contigs in fed fish contributed amongst others to terms like ion transport, protein complex assembly (Table 4), and "feeding behaviour" (Additional file 4: Table S2). In both fed and feed deprived charr, we found that up-regulated contigs over time were involved in basic cell metabolism processes such as DNA replication and RNA metabolism (Table 5)

Table 2 Number of up- and down-regulated transcripts in the different comparisons returned by EdgeR analysis. Cut-off at $\mathrm{FDR}<0.05$ and at LogFC 0.5/-0.5

\begin{tabular}{|c|c|c|c|c|c|}
\hline \multicolumn{2}{|c|}{$T_{1} \_$Fed versus $T_{0}$} & \multicolumn{2}{|c|}{$T_{1}$ FDP versus $T_{0}$} & \multicolumn{2}{|c|}{$T_{1}$ FDP versus $T_{1} \_F e d$} \\
\hline Up & Down & Up & Down & Up & Down \\
\hline 1534 & 1285 & 2616 & 1954 & 68 & 107 \\
\hline
\end{tabular}

. Contigs that were down-regulated over time regardless of the feeding regime were amongst others related to ion transport, protein related processes and wnt signaling (Table 6, Additional file 6: Table S4). Feed deprivation over time led to an up-regulation of contigs relating to processes such as catabolism, apoptosis and immune system (Table 7) and a down-regulation of e.g. oxygen transport (Table 8). An up-regulation of contigs that take part in catabolic and apoptotic processes and down-regulation of oxygen transport was also found in the endpoint comparison between FDP and fed charr (Additional file 9: Table S7, Table 9, Additional file 10: Table S8).

In an attempt to unravel whether central appetite signalling pathways in the charr brain transcriptome were modulated by feed-deprivation, we screened the lists of differentially expressed contigs systematically for candidate genes that have previously been demonstrated to be involved in the regulation of appetite and energy homeostasis in fish $[9,10]$. Further, due to a strong effect of season and temperature seen on the brain transcriptome (Fig. 3), genes involved in seasonal rhythms were included in the search. Lastly, we searched the dataset for possible new actors involved in the regulation of energy homeostasis and food intake, not previously described in fish.

Several candidate genes possibly involved in seasonality and food intake control in fish were found to be differentially expressed between one or several comparisons and are displayed in Table 10. Differences in expression were mainly found between the $T_{1}$ and $T_{0}$ for FDP and/or fed 


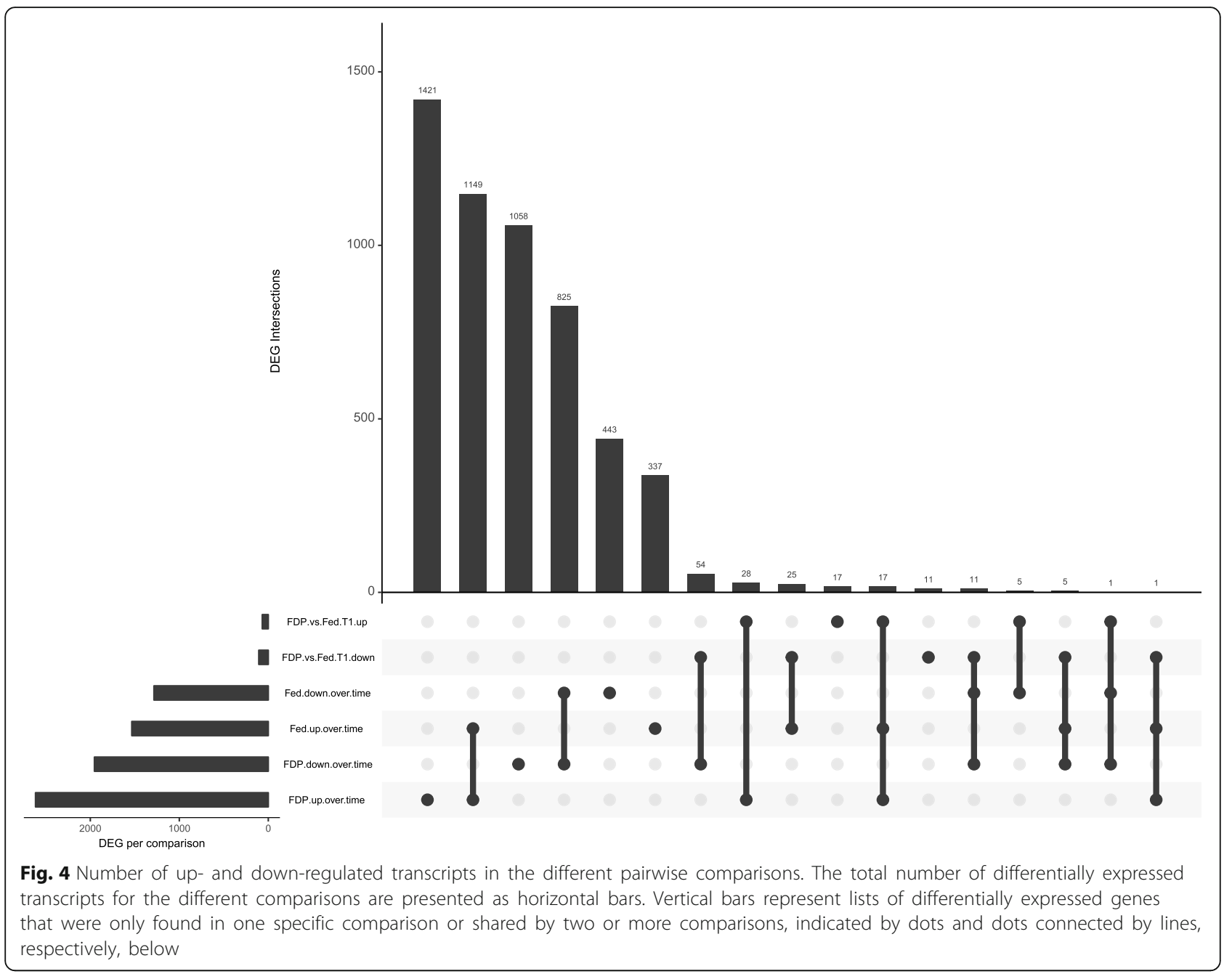

fish. Deiodinase $2 b$ (Dio2b) was also two-fold lower expressed in FDP charr than in fed charr at the end of the experiment (Fig. 5). The lists of top annotated genes that were found differentially expressed in the different comparisons (Additional file 11: Table S9, Additional file 12: Table S10, Additional file 13: Table S11, Additional file 14: Table S12, Additional file 15:
Table S13, and Additional file 16: Table S14) were screened for genes that, based on prior knowledge from mammals, are known to be involved in energy homeostasis and control of food intake. Here, the gene nerve growth factor inducible (VGF) was found as a new candidate that may be involved the regulation of appetite and energy metabolism in fish (Fig. 6).

Table 3 Biological processes enriched by up-regulated contigs only found in Fed versus $T_{0}$ (see yellow fraction in Venn diagram Additional file 1: Fig. S1). Terms sorted by the number of contributing contigs

\begin{tabular}{|c|c|c|c|c|c|}
\hline GO.ID & Term & Annotated & Significant & Expected & $p$-value \\
\hline GO:0006810 & Transport & 1483 & 25 & 14.54 & 0.0026 \\
\hline GO:0051234 & establishment of localization & 1484 & 25 & 14.55 & 0.0026 \\
\hline GO:0051179 & Localization & 1501 & 25 & 14.71 & 0.0031 \\
\hline GO:0044765 & single-organism transport & 883 & 19 & 8.66 & 0.0006 \\
\hline GO:1902578 & single-organism localization & 893 & 19 & 8.75 & 0.0007 \\
\hline GO:0015669 & gas transport & 16 & 10 & 0.16 & 3.20E-17 \\
\hline GO:0015671 & oxygen transport & 16 & 10 & 0.16 & $3.20 \mathrm{E}-17$ \\
\hline GO:0006457 & protein folding & 104 & 5 & 1.02 & 0.0034 \\
\hline
\end{tabular}


Table 4 Biological processes enriched by down-regulated contigs only found in Fed versus To (see yellow fraction in Venn diagram Additional file 1: Figure S1) Terms sorted by the number of contributing contigs

\begin{tabular}{|c|c|c|c|c|c|}
\hline GO.ID & Term & Annotated & Significant & Expected & $p$-value \\
\hline GO:0044765 & single-organism transport & 883 & 11 & 5.77 & 0.02405 \\
\hline GO:1902578 & single-organism localization & 893 & 11 & 5.84 & 0.02593 \\
\hline GO:0006811 & ion transport & 532 & 10 & 3.48 & 0.0019 \\
\hline GO:0006461 & protein complex assembly & 173 & 4 & 1.13 & 0.0258 \\
\hline GO:0070271 & protein complex biogenesis & 173 & 4 & 1.13 & 0.0258 \\
\hline GO:0065003 & macromolecular complex assembly & 189 & 4 & 1.24 & 0.03419 \\
\hline GO:0071822 & protein complex subunit organization & 189 & 4 & 1.24 & 0.03419 \\
\hline GO:0009966 & regulation of signal transduction & 212 & 4 & 1.39 & 0.04877 \\
\hline GO:0010646 & regulation of cell communication & 213 & 4 & 1.39 & 0.04947 \\
\hline GO:0023051 & regulation of signalling & 213 & 4 & 1.39 & 0.04947 \\
\hline
\end{tabular}

\section{Data release}

Our raw RNA-seq data are available in the SRA database [24] under accession number SRP151983. In addition, we specifically developed an interface for the present de novo transcriptome. The entire dataset can be browsed at the following URL: http://ngspipelines2.toulouse.inra. fr:9002/ the main menu enables the user to enter the contigs, SNPs and download sections. The contig section main page displays three blocks providing (1) statistics upon the assembly and the annotations, (2) information and access to statistical analysis tools (digital differential display, Venn diagram) on the library and (3) a table that displays data of the contigs that are of the user's strongest interest. Once a contig has been selected, the user can view its general annotation including Gene Ontology, check its sequence for possible open reading frames, visualize the annotation location in the "jbrowse view" and scan the alignment coverage along the contig for each library. All these features are accessible through the menu located at the top of the page. The SNP section has also a main page presenting some statistics and the favourite table. Once a variable locus is selected, the user can access general information such as the list of alleles and the flanking sequences, allele information with the allele count graph and table for each library and the corresponding functional annotation.

\section{Discussion}

\section{Feed deprived and fed charr showed a diverging} development of weight and condition

The strong increase in $K$ and body mass observed over the 4 weeks period in the fed charr (Fig. 1) was consistent with the high food intake and growth of anadromous Arctic charr during summer $[17,25]$. The FDP charr underwent a strong mobilization of energy reserves during the experiment resulting in a markedly lower $K$ and body mass in FDP charr than in fed charr at $\mathrm{T}_{1}$ (Fig. 1). This effect of treatment was also evident in the 5 fish from each treatment sampled for transcriptome analyses.

\section{A reliable de novo brain transcriptome}

Out of the 49829 generated contigs, more than $85 \%$ were annotated, mainly based on Atlantic salmon (Fig. 2). This was expected as Atlantic salmon was phylogenetically the closest related species with a sequenced genome at the time the charr de novo transcriptome was built (spring 2016) [26]. Besides other teleost species contributing to the annotation, Homo sapiens also gave hits: the human genome is well characterized and might have brought annotations of genes that, so far, have only been described in humans.

Even if it is known for its complex transcriptomic signature, the brain alone cannot be representative of the entire diversity of the Arctic charr transcriptome. Thus, a completeness of $67 \%$ (BUSCO analysis) confirmed that the assembly produced correct contigs. Indeed other fish transcriptome de novo assemblies brought results in the same order of magnitude with $70.2 \%$ completeness for the gut tench (Tinca tinca) [27] and 64\% for 4 combined tissues of the noble crayfish (Astacus astacus) [28]. In addition, (1) the comparison to the phylogenetically close Atlantic salmon reference proteome, (2) the calculation of the realignment rates and (3) the mapping of an Arctic charr public raw data using a de novo assembly from short read RNA-seq data on our dataset also confirmed a high completeness of the built transcriptome.

\section{Global brain gene expression patterns differ over time while feed deprivation has a moderate impact}

The correlation heatmap highlighted that charr brain transcriptomes from $\mathrm{T}_{0}$ clustered together and were markedly different from the ones sampled at $\mathrm{T}_{1}$. Samples of the fed and FDP charr at $\mathrm{T}_{1}$ did not cluster in accordance with the treatment group. These results stand in contrast with the strong divergence in $K$ and weight 
Table 5 Biological processes enriched by up-regulated contigs found in Fed versus $T_{0}$ and FDP versus $T_{0}$ (see white fraction in Venn diagram Additional file 1: Figure S1). Terms sorted by the number of contributing contigs

\begin{tabular}{|c|c|c|c|c|c|}
\hline GO.ID & Term & Annotated & Significant & Expected & $p$-value \\
\hline GO:0019438 & aromatic compound biosynthetic process & 782 & 28 & 16 & 0.0021 \\
\hline GO:0018130 & heterocycle biosynthetic process & 796 & 28 & 16.28 & 0.0027 \\
\hline GO:1901362 & organic cyclic compound biosynthetic process & 803 & 28 & 16.43 & 0.0031 \\
\hline GO:0034654 & nucleobase-containing compound biosynthetic process & 750 & 25 & 15.34 & 0.0092 \\
\hline GO:0080090 & regulation of primary metabolic process & 622 & 24 & 12.72 & 0.0017 \\
\hline GO:0031323 & regulation of cellular metabolic process & 632 & 24 & 12.93 & 0.0021 \\
\hline GO:0019222 & regulation of metabolic process & 641 & 24 & 13.11 & 0.0025 \\
\hline GO:0019219 & regulation of nucleobase-containing compound metabolic process & 577 & 23 & 11.8 & 0.0014 \\
\hline GO:0051171 & regulation of nitrogen compound metabolic process & 587 & 23 & 12.01 & 0.0017 \\
\hline GO:0060255 & regulation of macromolecule metabolic process & 619 & 23 & 12.66 & 0.0034 \\
\hline GO:0006355 & regulation of transcription, DNA-templated & 568 & 22 & 11.62 & 0.0025 \\
\hline GO:1903506 & regulation of nucleic acid-templated transcription & 568 & 22 & 11.62 & 0.0025 \\
\hline GO:2001141 & regulation of RNA biosynthetic process & 569 & 22 & 11.64 & 0.0026 \\
\hline GO:0051252 & regulation of RNA metabolic process & 572 & 22 & 11.7 & 0.0028 \\
\hline GO:0010556 & regulation of macromolecule biosynthetic process & 580 & 22 & 11.87 & 0.0033 \\
\hline GO:2000112 & regulation of cellular macromolecule biosynthetic process & 580 & 22 & 11.87 & 0.0033 \\
\hline GO:0031326 & regulation of cellular biosynthetic process & 581 & 22 & 11.89 & 0.0034 \\
\hline GO:0009889 & regulation of biosynthetic process & 582 & 22 & 11.91 & 0.0034 \\
\hline GO:0010468 & regulation of gene expression & 583 & 22 & 11.93 & 0.0035 \\
\hline GO:0006351 & transcription, DNA-templated & 630 & 22 & 12.89 & 0.0087 \\
\hline GO:0097659 & nucleic acid-templated transcription & 630 & 22 & 12.89 & 0.0087 \\
\hline GO:0032774 & RNA biosynthetic process & 633 & 22 & 12.95 & 0.0092 \\
\hline GO:0051276 & chromosome organization & 94 & 7 & 1.92 & 0.003 \\
\hline GO:0006325 & chromatin organization & 72 & 6 & 1.47 & 0.0034 \\
\hline GO:0006955 & immune response & 50 & 5 & 1.02 & 0.0034 \\
\hline GO:0002376 & immune system process & 52 & 5 & 1.06 & 0.004 \\
\hline GO:0016571 & histone methylation & 11 & 3 & 0.23 & 0.0012 \\
\hline GO:0018022 & peptidyl-lysine methylation & 11 & 3 & 0.23 & 0.0012 \\
\hline GO:0034968 & histone lysine methylation & 11 & 3 & 0.23 & 0.0012 \\
\hline GO:0018205 & peptidyl-lysine modification & 22 & 3 & 0.45 & 0.0097 \\
\hline GO:0016569 & covalent chromatin modification & 23 & 3 & 0.47 & 0.011 \\
\hline GO:0016570 & histone modification & 23 & 3 & 0.47 & 0.011 \\
\hline GO:0019882 & antigen processing and presentation & 26 & 3 & 0.53 & 0.0154 \\
\hline GO:0006479 & protein methylation & 27 & 3 & 0.55 & 0.0171 \\
\hline GO:0008213 & protein alkylation & 27 & 3 & 0.55 & 0.0171 \\
\hline GO:0033993 & response to lipid & 28 & 3 & 0.57 & 0.0189 \\
\hline GO:0043401 & steroid hormone mediated signaling pathway & 28 & 3 & 0.57 & 0.0189 \\
\hline GO:0048545 & response to steroid hormone & 28 & 3 & 0.57 & 0.0189 \\
\hline GO:0071383 & cellular response to steroid hormone stimulus & 28 & 3 & 0.57 & 0.0189 \\
\hline GO:0071396 & cellular response to lipid & 28 & 3 & 0.57 & 0.0189 \\
\hline GO:0014070 & response to organic cyclic compound & 29 & 3 & 0.59 & 0.0208 \\
\hline GO:0071407 & cellular response to organic cyclic compound & 29 & 3 & 0.59 & 0.0208 \\
\hline GO:0009725 & response to hormone & 31 & 3 & 0.63 & 0.0248 \\
\hline
\end{tabular}


Table 5 Biological processes enriched by up-regulated contigs found in Fed versus $T_{0}$ and FDP versus $T_{0}$ (see white fraction in Venn diagram Additional file 1: Figure S1). Terms sorted by the number of contributing contigs (Continued)

\begin{tabular}{|c|c|c|c|c|c|}
\hline GO.ID & Term & Annotated & Significant & Expected & $p$-value \\
\hline GO:0009755 & hormone-mediated signaling pathway & 31 & 3 & 0.63 & 0.0248 \\
\hline GO:0032870 & cellular response to hormone stimulus & 31 & 3 & 0.63 & 0.0248 \\
\hline GO:0018193 & peptidyl-amino acid modification & 34 & 3 & 0.7 & 0.0316 \\
\hline GO:0006334 & nucleosome assembly & 35 & 3 & 0.72 & 0.0341 \\
\hline GO:0016568 & chromatin modification & 35 & 3 & 0.72 & 0.0341 \\
\hline GO:0031497 & chromatin assembly & 35 & 3 & 0.72 & 0.0341 \\
\hline GO:0034728 & nucleosome organization & 35 & 3 & 0.72 & 0.0341 \\
\hline GO:0006323 & DNA packaging & 36 & 3 & 0.74 & 0.0366 \\
\hline GO:0006333 & chromatin assembly or disassembly & 37 & 3 & 0.76 & 0.0393 \\
\hline
\end{tabular}

between the fed and FDP charr. However, feed deprivation may only have affected very specific processes in the brain transcriptome leaving the overall expression pattern less strongly affected.

Seasonal changes alone (including the increased water temperature), or in combination with feed deprivation, induced a high number of differing contigs from start to end of the experiment, compared to the minor differences observed between the treatment groups at the endpoint. This pattern depicts strong shifts in the charr brain gene expression over a 4 weeks period during summer, which occurred regardless of feeding regime (Fig. 4) . The results underline that seasonal processes, including changes in water temperature and summer growth, have much stronger effects on the brain transcriptome in the charr than 1 month of feed deprivation during the feeding season. However, the two times higher number of differentially expressed contigs over time in the feed deprived charr than in the fed conspecifics may suggest an enhancement of seasonal differences by feed deprivation (Table 2). The large changes seen over time correspond with an earlier transcriptome study on different Arctic charr morphs, where time, in that case during early development, was the most important factor for differentially expressed transcripts [29].

In addition, the Up-set graphs (Fig.4) showed that a larger fraction of both up- and down-regulated contigs differed only in response to feed deprivation. On the other hand, most of the differences found in the fed fish were at the same time found in the FDP charr. These shared differences over time depict robust seasonal processes that remain unaffected by feed availability.

\section{Food deprivation partially offsets increase in brain metabolism during summer growth Feeding specific differences over time}

Up-regulated contigs over time denoted foremost oxygen transport (genes encoding for several haemoglobin (Hb) subunits) and protein related biological processes (Table 3). Brain $H b$ mRNA has been found in rodents and humans [30] and it has been suggested that neural haemoglobin may facilitate oxygen transport in neurons [31], but the exact mechanism remains unknown. In addition, it cannot be ruled that the cDNA library may

Table 6 Biological processes enriched by down-regulated contigs found in Fed versus $T_{0}$ and FDP versus $T_{0}$ (see white fraction in Venn diagram Additional file 1: Figure S1). Terms sorted by the number of contributing contigs

\begin{tabular}{|c|c|c|c|c|c|}
\hline GO.ID & Term & Annotated & Significant & Expected & $p$-value \\
\hline GO:0044699 & single-organism process & 3629 & 54 & 45.37 & 0.04 \\
\hline GO:0044765 & single-organism transport & 883 & 17 & 11.04 & 0.0443 \\
\hline GO:1902578 & single-organism localization & 893 & 17 & 11.16 & 0.0485 \\
\hline GO:0006811 & ion transport & 532 & 12 & 6.65 & 0.0322 \\
\hline GO:0006470 & protein dephosphorylation & 126 & 6 & 1.58 & 0.0048 \\
\hline GO:0016311 & dephosphorylation & 162 & 6 & 2.03 & 0.0156 \\
\hline GO:0015672 & monovalent inorganic cation transport & 175 & 6 & 2.19 & 0.0219 \\
\hline GO:0006813 & potassium ion transport & 88 & 4 & 1.1 & 0.024 \\
\hline GO:0006457 & protein folding & 104 & 4 & 1.3 & 0.0408 \\
\hline GO:0051258 & protein polymerization & 36 & 3 & 0.45 & 0.01 \\
\hline
\end{tabular}


Table 7 Biological processes enriched by up-regulated contigs only found in FDP versus $T_{0}$ (see blue fraction in Venn diagram Additional file 1: Figure S1). Terms sorted by the number of contributing contigs

\begin{tabular}{|c|c|c|c|c|c|}
\hline GO.ID & Term & Annotated & Significant & Expected & $p$-value \\
\hline GO:0065007 & biological regulation & 2021 & 62 & 47.66 & 0.00925 \\
\hline GO:0050789 & regulation of biological process & 1973 & 61 & 46.53 & 0.00837 \\
\hline GO:0050794 & regulation of cellular process & 1934 & 59 & 45.61 & 0.01308 \\
\hline GO:0006725 & cellular aromatic compound metabolic process & 1375 & 42 & 32.43 & 0.03914 \\
\hline GO:0090304 & nucleic acid metabolic process & 1097 & 35 & 25.87 & 0.03448 \\
\hline GO:0016070 & RNA metabolic process & 884 & 30 & 20.85 & 0.02407 \\
\hline GO:0060255 & regulation of macromolecule metabolic process & 619 & 22 & 14.6 & 0.03315 \\
\hline GO:0080090 & regulation of primary metabolic process & 622 & 22 & 14.67 & 0.03473 \\
\hline GO:0031323 & regulation of cellular metabolic process & 632 & 22 & 14.9 & 0.04041 \\
\hline GO:0019222 & regulation of metabolic process & 641 & 22 & 15.12 & 0.04609 \\
\hline GO:0051252 & regulation of RNA metabolic process & 572 & 20 & 13.49 & 0.04778 \\
\hline GO:0006396 & RNA processing & 189 & 10 & 4.46 & 0.01367 \\
\hline GO:0006955 & immune response & 50 & 7 & 1.18 & 0.00015 \\
\hline GO:0002376 & immune system process & 52 & 7 & 1.23 & 0.0002 \\
\hline GO:0008219 & cell death & 58 & 6 & 1.37 & 0.00231 \\
\hline GO:0016265 & death & 58 & 6 & 1.37 & 0.00231 \\
\hline GO:0010941 & regulation of cell death & 45 & 5 & 1.06 & 0.00391 \\
\hline GO:0042981 & regulation of apoptotic process & 45 & 5 & 1.06 & 0.00391 \\
\hline GO:0043067 & regulation of programmed cell death & 45 & 5 & 1.06 & 0.00391 \\
\hline GO:0006915 & apoptotic process & 57 & 5 & 1.34 & 0.0107 \\
\hline GO:0012501 & programmed cell death & 57 & 5 & 1.34 & 0.0107 \\
\hline GO:0048518 & positive regulation of biological process & 67 & 5 & 1.58 & 0.02048 \\
\hline GO:0006397 & mRNA processing & 68 & 5 & 1.6 & 0.0217 \\
\hline GO:0016071 & mRNA metabolic process & 79 & 5 & 1.86 & 0.03824 \\
\hline GO:0019882 & antigen processing and presentation & 26 & 4 & 0.61 & 0.00297 \\
\hline GO:0051726 & regulation of cell cycle & 40 & 4 & 0.94 & 0.01409 \\
\hline GO:0015074 & DNA integration & 55 & 4 & 1.3 & 0.04013 \\
\hline GO:0010942 & positive regulation of cell death & 13 & 3 & 0.31 & 0.0031 \\
\hline GO:0043065 & positive regulation of apoptotic process & 13 & 3 & 0.31 & 0.0031 \\
\hline GO:0043068 & positive regulation of programmed cell death & 13 & 3 & 0.31 & 0.0031 \\
\hline GO:0007050 & cell cycle arrest & 18 & 3 & 0.42 & 0.0081 \\
\hline GO:0045786 & negative regulation of cell cycle & 21 & 3 & 0.5 & 0.01254 \\
\hline GO:0008380 & RNA splicing & 26 & 3 & 0.61 & 0.0225 \\
\hline
\end{tabular}

have contained RNA from non-neuronal tissue including blood vessels and veins, e.g. derived from the highly vascularised saccus vasculosus. The metabolic rate of ectotherms is directly linked to ambient temperature. Specifically, the temperature of optimal growth performance of Arctic charr from NorthNorway has been shown to be $14^{\circ} \mathrm{C}$ [32]. The increase in water temperature by almost $10{ }^{\circ} \mathrm{C}$ during our study may have involved an increase in metabolic rate of Arctic charr. Hence, the observed increase in expression of genes encoding oxygen transporters may have occurred in order to meet increased oxygen demands at higher temperatures.

Furthermore, the feeding related terms such as "feeding behaviour" and "negative regulation of appetite" appeared in the list of GO terms of down-regulated contigs. The contig that contributed to these GO terms was the anorexigenic neuropeptide $C A R T$, thus suggesting an increase in appetite in the fed charr over time (Additional file 4: Table S2). The decrease in CART expression is discussed in detail in the paragraph on candidate appetite regulators. 
Table 8 Biological processes enriched by down-regulated contigs only found FDP versus $T_{0}$ (see blue fraction in Venn diagram Additional file 1: Figure S1). Terms sorted by the number of contributing contigs

\begin{tabular}{|c|c|c|c|c|c|}
\hline GO.ID & Term & Annotated & Significant & Expected & $p$-value \\
\hline GO:0006807 & nitrogen compound metabolic process & 1736 & 66 & 53.76 & 0.03251 \\
\hline GO:1901360 & organic cyclic compound metabolic process & 1400 & 55 & 43.36 & 0.0299 \\
\hline GO:0009058 & biosynthetic process & 1439 & 55 & 44.57 & 0.04759 \\
\hline GO:1901576 & organic substance biosynthetic process & 1374 & 54 & 42.55 & 0.03127 \\
\hline GO:0044249 & cellular biosynthetic process & 1358 & 53 & 42.06 & 0.03699 \\
\hline GO:0006725 & cellular aromatic compound metabolic process & 1375 & 53 & 42.58 & 0.0453 \\
\hline GO:1901564 & organonitrogen compound metabolic process & 620 & 28 & 19.2 & 0.02644 \\
\hline GO:0016043 & cellular component organization & 466 & 23 & 14.43 & 0.01725 \\
\hline GO:0071840 & cellular component organization or biogenesis & 499 & 23 & 15.45 & 0.03484 \\
\hline GO:1901566 & organonitrogen compound biosynthetic process & 451 & 21 & 13.97 & 0.039 \\
\hline GO:0006508 & proteolysis & 298 & 18 & 9.23 & 0.00495 \\
\hline GO:0022607 & cellular component assembly & 222 & 13 & 6.88 & 0.02012 \\
\hline GO:0034622 & cellular macromolecular complex assembly & 127 & 12 & 3.93 & 0.00054 \\
\hline GO:0007017 & microtubule-based process & 132 & 12 & 4.09 & 0.00076 \\
\hline GO:0006461 & protein complex assembly & 173 & 12 & 5.36 & 0.00728 \\
\hline GO:0070271 & protein complex biogenesis & 173 & 12 & 5.36 & 0.00728 \\
\hline GO:0065003 & macromolecular complex assembly & 189 & 12 & 5.85 & 0.01414 \\
\hline GO:0071822 & protein complex subunit organization & 189 & 12 & 5.85 & 0.01414 \\
\hline GO:0006082 & organic acid metabolic process & 226 & 12 & 7 & 0.04764 \\
\hline GO:0019752 & carboxylic acid metabolic process & 226 & 12 & 7 & 0.04764 \\
\hline GO:0043436 & oxoacid metabolic process & 226 & 12 & 7 & 0.04764 \\
\hline GO:0006520 & cellular amino acid metabolic process & 126 & 10 & 3.9 & 0.00554 \\
\hline GO:0051258 & protein polymerization & 36 & 9 & 1.11 & $1.00 \mathrm{E}-06$ \\
\hline GO:0043623 & cellular protein complex assembly & 76 & 9 & 2.35 & 0.00052 \\
\hline GO:0006457 & protein folding & 104 & 9 & 3.22 & 0.00477 \\
\hline GO:0030163 & protein catabolic process & 118 & 8 & 3.65 & 0.02963 \\
\hline GO:1902582 & single-organism intracellular transport & 88 & 7 & 2.73 & 0.01889 \\
\hline GO:0044257 & cellular protein catabolic process & 100 & 7 & 3.1 & 0.03502 \\
\hline GO:0051603 & proteolysis involved in cellular protein catabolic process & 100 & 7 & 3.1 & 0.03502 \\
\hline GO:1901605 & alpha-amino acid metabolic process & 58 & 5 & 1.8 & 0.03302 \\
\hline GO:0006270 & DNA replication initiation & 4 & 4 & 0.12 & $9.00 \mathrm{E}-07$ \\
\hline GO:0006261 & DNA-dependent DNA replication & 5 & 4 & 0.15 & 4.40E-06 \\
\hline GO:0006839 & mitochondrial transport & 16 & 4 & 0.5 & 0.00121 \\
\hline GO:0009069 & serine family amino acid metabolic process & 20 & 4 & 0.62 & 0.00293 \\
\hline GO:0008652 & cellular amino acid biosynthetic process & 31 & 4 & 0.96 & 0.01461 \\
\hline GO:1901607 & alpha-amino acid biosynthetic process & 31 & 4 & 0.96 & 0.01461 \\
\hline GO:0071103 & DNA conformation change & 44 & 4 & 1.36 & 0.04628 \\
\hline GO:0009070 & serine family amino acid biosynthetic process & 7 & 3 & 0.22 & 0.00094 \\
\hline GO:0031032 & actomyosin structure organization & 7 & 3 & 0.22 & 0.00094 \\
\hline GO:0000278 & mitotic cell cycle & 14 & 3 & 0.43 & 0.00828 \\
\hline GO:0006720 & isoprenoid metabolic process & 14 & 3 & 0.43 & 0.00828 \\
\hline GO:0008299 & isoprenoid biosynthetic process & 14 & 3 & 0.43 & 0.00828 \\
\hline GO:1903047 & mitotic cell cycle process & 14 & 3 & 0.43 & 0.00828 \\
\hline
\end{tabular}


Table 8 Biological processes enriched by down-regulated contigs only found FDP versus $T_{0}$ (see blue fraction in Venn diagram Additional file 1: Figure S1). Terms sorted by the number of contributing contigs (Continued)

\begin{tabular}{|c|c|c|c|c|c|}
\hline GO.ID & Term & Annotated & Significant & Expected & $p$-value \\
\hline GO:0015669 & gas transport & 16 & 3 & 0.5 & 0.01218 \\
\hline GO:0015671 & oxygen transport & 16 & 3 & 0.5 & 0.01218 \\
\hline
\end{tabular}

\section{Feed deprivation specific differences over time}

In the FDP charr, up-regulated contigs were associated with processes such as catabolism, apoptosis, and immune function (Table 7). In contrast, no such trends were found in brain transcriptome analyses of 21-day feed-deprived zebrafish [33]. The finding that contigs relating to apoptosis were increased is puzzling, given the consensus that the brain is well protected from starvation in both mammals [34] and fish [35]. However, in mammals, there is a debate on to what extend feed deprivation may initiate a degeneration of the central nervous system, as different studies have given indication for both absence [36] and presence [37] of autophagy in the brain of feed deprived mice. Further experiments are needed to test whether the observed up-regulation of contigs involved in apoptosis were a sign of neuronal degradation in charr.
Furthermore, we found the GO term "ketone body catabolic process", comprising the gene encoding 3oxoacid CoA transferase, to be up-regulated in the feed deprived charr, pointing towards an increase in ketone catabolic activity from start to the end of experiment (Additional file 7: Table S5). This is in line with previous studies on Atlantic salmon and rainbow trout, where ketone bodies were found to serve as an important energy source for the brain when food is absent [38, 39].

In contrast to the fed charr, contigs pertaining to oxygen transport were down-regulated in feed deprived charr (Table 8). This finding is in agreement with the down-regulation of transcripts related to oxygen transport in response to feed deprivation previously seen in Atlantic salmon liver transcriptome [40], rainbow trout liver transcriptome [41] and in zebrafish brain transcriptome [33]. The lower expression of $H b$ in feed deprived

Table 9 Biological processes enriched by down-regulated contigs comparing feed deprived versus fed charr at end of experiment. Terms sorted by the number of contributing contigs

\begin{tabular}{|c|c|c|c|c|c|}
\hline GO.ID & Term & Annotated & Significant & Expected & $p$-value \\
\hline GO:0006810 & transport & 1483 & 15 & 8.85 & 0.02027 \\
\hline GO:0051234 & establishment of localization & 1484 & 15 & 8.85 & 0.02039 \\
\hline GO:0051179 & localization & 1501 & 15 & 8.96 & 0.0225 \\
\hline GO:0044765 & single-organism transport & 883 & 14 & 5.27 & 0.00038 \\
\hline GO:1902578 & single-organism localization & 893 & 14 & 5.33 & 0.00043 \\
\hline GO:0015669 & gas transport & 16 & 11 & 0.1 & $3.50 \mathrm{E}-22$ \\
\hline GO:0015671 & oxygen transport & 16 & 11 & 0.1 & $3.50 \mathrm{E}-22$ \\
\hline GO:0006259 & DNA metabolic process & 228 & 6 & 1.36 & 0.00214 \\
\hline GO:0006260 & DNA replication & 113 & 5 & 0.67 & 0.00052 \\
\hline GO:0006270 & DNA replication initiation & 4 & 4 & 0.02 & 1.10E-09 \\
\hline GO:0006261 & DNA-dependent DNA replication & 5 & 4 & 0.03 & $5.50 \mathrm{E}-09$ \\
\hline GO:0051258 & protein polymerization & 36 & 4 & 0.21 & $5.60 \mathrm{E}-05$ \\
\hline GO:0043623 & cellular protein complex assembly & 76 & 4 & 0.45 & 0.00103 \\
\hline GO:0034622 & cellular macromolecular complex assembly & 127 & 4 & 0.76 & 0.00666 \\
\hline GO:0006461 & protein complex assembly & 173 & 4 & 1.03 & 0.01908 \\
\hline GO:0070271 & protein complex biogenesis & 173 & 4 & 1.03 & 0.01908 \\
\hline GO:0065003 & macromolecular complex assembly & 189 & 4 & 1.13 & 0.02546 \\
\hline GO:0071822 & protein complex subunit organization & 189 & 4 & 1.13 & 0.02546 \\
\hline GO:0022607 & cellular component assembly & 222 & 4 & 1.32 & 0.04232 \\
\hline GO:0007017 & microtubule-based process & 132 & 3 & 0.79 & 0.04352 \\
\hline
\end{tabular}


Table 10 Differentially expressed candidate genes involved in food intake control and seasonality

\begin{tabular}{|c|c|c|c|c|c|c|c|c|}
\hline \multirow[b]{2}{*}{ Gene Name } & \multirow[b]{2}{*}{ ContiglD } & \multirow[b]{2}{*}{ Accession No. } & \multicolumn{2}{|c|}{$\mathrm{T}_{1}$ Fed vs $\mathrm{T}_{0}$} & \multicolumn{2}{|c|}{$\mathrm{T}_{1} \_\mathrm{FDP}$ vs $\mathrm{T}_{0}$} & \multicolumn{2}{|c|}{$\mathrm{T}_{1 \_}$FDP vs $\mathrm{T}_{1 \_}$Fed } \\
\hline & & & LOG FC & $P$ value & LOG FC & $P$ value & LOG FC & $P$ value \\
\hline Apelin receptor $A$ & Fishapp_brain_apja.2.3 & NM_001140368.1 & 0.99 & 0.003 & - & - & - & - \\
\hline $\begin{array}{l}\text { Cocaine and amphetamine } \\
\text { regulated transcript }\end{array}$ & Fishapp_brain_contig_33002 & NM_001146680.1 & -0.66 & $<0.001$ & -0.33 & 0.006 & - & - \\
\hline \multirow[t]{3}{*}{ Cholecystokinin } & Fishapp_brain_contig_18503 & NM_001139522.1 & - & - & - & - & - & - \\
\hline & Fishapp_brain_contig_21023 & & - & - & - & - & - & - \\
\hline & Fishapp_brain_contig_17948 & & - & - & -0.37 & 0.003 & - & - \\
\hline Corticotropin-releasing factor & Fishapp_brain_contig_16188 & NM_001124627.1 & - & - & -0.55 & 0.008 & - & - \\
\hline \multirow[t]{2}{*}{ Deiodinase $2 b$} & Fishapp_brain_contig_18436 & NM_001124268.1 & -0.60 & 0.003 & -1.79 & $<0.001$ & -1.19 & $<0.001$ \\
\hline & Fishapp_brain_contig_15175 & & -1.21 & $>0.001$ & -2.02 & $<0.001$ & -0.81 & $<0.001$ \\
\hline Insulin like growth factor 1 & Fishapp_brain_IGF1 & GU933431.1 & - & - & -0.81 & 0.003 & - & - \\
\hline Leptin & Fishapp_brain_lepb1 & $J \times 131305.1$ & 1.701 & $<0.001$ & 1.37 & $<0.001$ & - & - \\
\hline Neuropeptide Y & Fishapp_brain_npy & NM_001146681.1 & -0.55 & $<0.001$ & - & - & - & - \\
\hline Proopiomelanocortin & Fishapp_brain_contig_04399 & XM_024143555.1 & - & - & 5.99 & 0.001 & - & - \\
\hline Tachykinin 1 & Fishapp_brain_contig_09262 & XM_023974799.1 & - & - & -0.51 & 0.002 & - & - \\
\hline
\end{tabular}

Genes found in the transcriptome, but no difference in expression:

Apelin, Agouti related peptide, Arginine vasotocin, Galanin, Melanin concentrating hormone, Peptide YY, Thyroid releasing hormone

Genes searched, but not present in the transcriptome:

Ghrelin, Kisspeptin, Leptin receptor, Melanocortin receptor 4, Obestatin, Octadecaneuropeptide, Orexin, Pituitary adenylate cyclase-activating polypeptide, Prolactin

releasing peptide, Secretoneurin

charr may be related to a metabolic suppression in FDP fish in order to save energy when feed is absent. Brain metabolic suppression, indicated by a reduction of glucose oxidation has previously been observed in feed deprived rainbow trout [39]. However, these feed deprived rainbow trout showed a decrease in hexokinase and 6phosphofruktokinase activities in the brain. In contrast, expression of these glycolytic enzymes did not differ between fed and FDP charr in the present study.

Differences between fed and feed deprived charr at the end of the experiment

At $\mathrm{T}_{1}$, there was an up-regulation of contigs involved in biological processes related to apoptosis by feed

\section{Dio2b}

Fishapp_brain_contig_18436

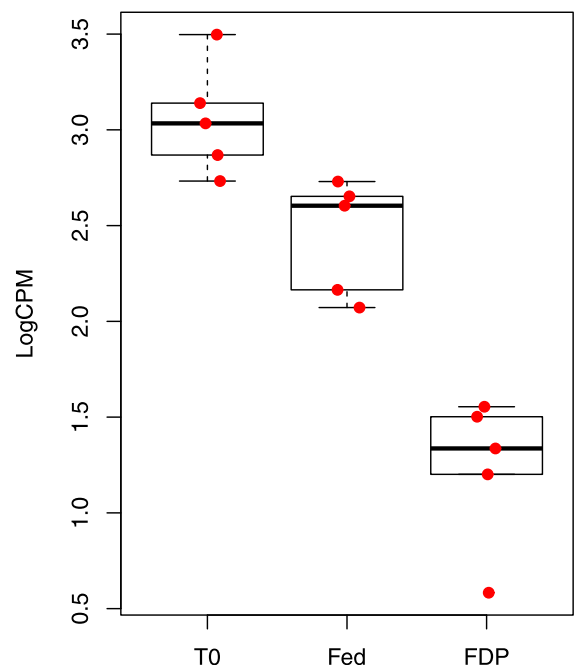

Fishapp_brain_contig_15175

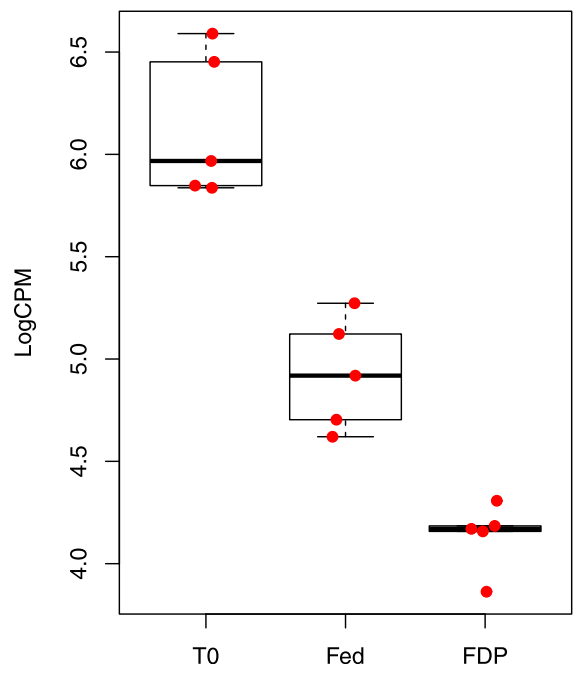

Fig. 5 Log counts per million reads (logCPM) for contigs corresponding to Dio2b in the three treatment groups. Data are presented as box and whisker plots with median, 25 th and 75 th percentiles and $1.5 *$ interquartile range. In addition, individual data points are indicated within the plot 


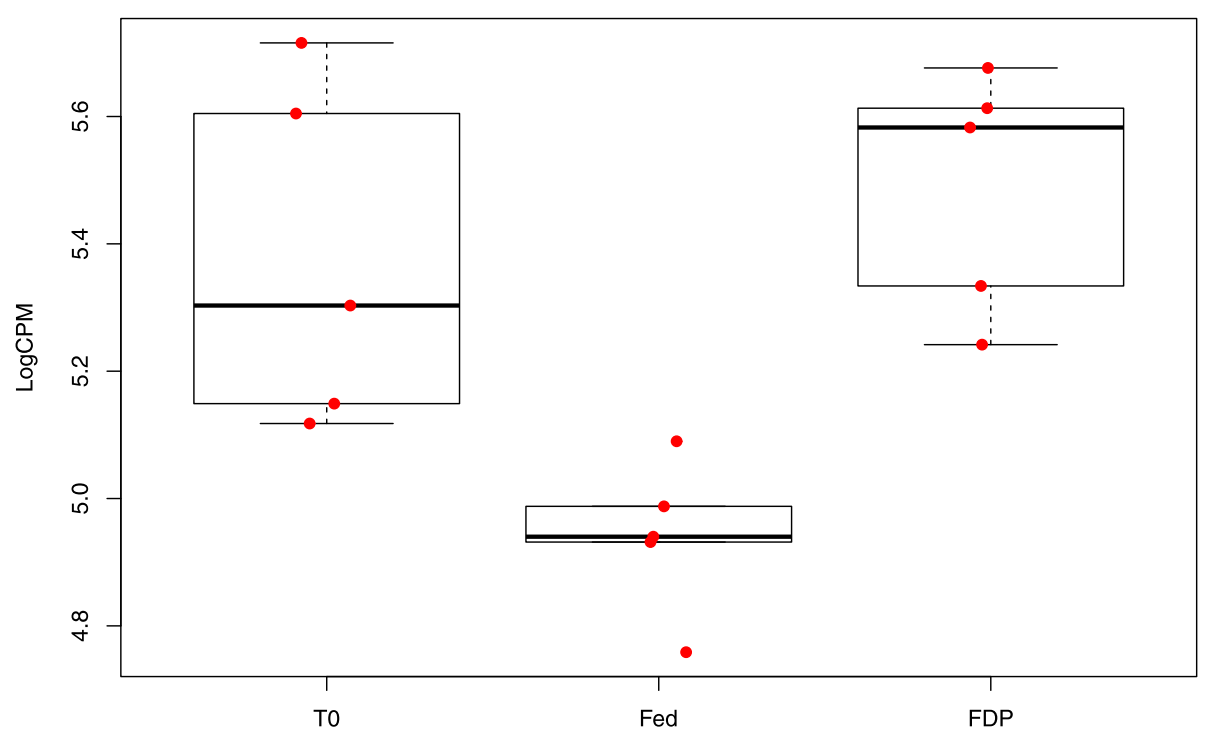

Fig. 6 Log counts per million reads (logCPM) for the contig vgf3.3 in the three treatment groups. Data are presented as box and whisker plots with median, 25th and 75th percentiles and $1.5 *$ interquartile range. In addition, individual data points are indicated within the plot

deprivation as well as a down-regulation of biological processes related to oxygen transport (Additional file 9: Table S7, Table 9, Additional file 12: Table S10). These findings further support the possibility that brain metabolic processes may have been partly impaired by feed deprivation, as the changes were both visible over time and between the fed and FDP fish at the end of the experiment.

\section{Differences over time regardless of feeding regime}

Over time, there was an up-regulation of contigs involved in biological processes such as DNA replication, RNA metabolism, response to steroid hormones and immune response (Table 5). This may indicate that basic cell metabolic processes such as cell proliferation and neuronal development were positively affected by seasonal growth and temperature. At the same time, there was a down-regulation of contigs affecting biological processes such as ion transport, protein related processes and wnt signalling from start to end of the experiment (Additional file 6: Table S4).

Interestingly, in adult zebrafish, activation and deactivation of wnt signalling in a sequential manner has been shown to accommodate proliferation and differentiation of progenitor cells in the hypothalamus [42]. Furthermore, the finding that wnt signalling in the ARC was stimulated by leptin in mouse [43] and by both leptin and long photoperiod in the seasonal Djungarian hamster (Phodopus sungorus) [44] have triggered a discussion for a role of hypothalamic wnt signalling in the seasonal control of energy balance [45]. Yet, we only found differences in expression for WNT4, and the question of a possible seasonal related function of wnt signalling in charr requires further study.

Taken together, the results from the GO analyses indicate that the enforced energy perturbation by feed deprivation may have affected several metabolic processes in the brain at the mRNA level. Yet, most elementary biological processes, including cell division processes and immune responses, differed similarly over time in both fed and feed deprived charr.

Effect of feed deprivation on candidate genes involved in the regulation of appetite and energy metabolism in fish Expression patterns of known anorexigenic and orexigenic neuropeptides do not indicate an amplified hunger signalling in feed deprived charr

Despite the lower weight and $K$ in feed deprived charr, expression of central appetite regulators did not reflect the feeding regime of the fish (Table 10). Several genes differed in one or both feeding regimes over time, but none between FDP and fish at $\mathrm{T}_{1}$. There was a lower expression of the anorexigenic CART at $\mathrm{T}_{1}$ in both fed ( $\operatorname{LogFC}=-$ $0.66)$ and FDP $(\operatorname{LogFC}=-0.33)$ charr than in fed charr at $\mathrm{T}_{0}$ (Table 10). If CART exhibits an anorexigenic function in charr, the lower expression of CART in both fed and FDP fish over time points towards a seasonal increase in hunger signalling in both treatment groups, but no response to feed deprivation. This corresponds to the lack of responses in hypothalamic CART expression seen in previous long-term feed deprivation studies with rainbow 
trout (4 months) and Arctic charr (4 weeks) [19, 46]. In contrast, brain CART expression decreased in zebrafish after 3 days feed deprivation [47], in Atlantic salmon after 6 days of feed deprivation [48] and in Atlantic cod (Gadus morhua) after 7 days feed deprivation [49].

Being described as a potent satiety signal in mammals and several fish species, hypothalamic POMCA had, unexpectedly, markedly $(\operatorname{LogFC}=5.99)$ higher expression levels in FDP charr at $\mathrm{T}_{1}$ than in charr sampled at $\mathrm{T}_{0}$. In contrast to the results seen for CART, this finding may suggest a decrease in hunger signalling in FDP charr over time. This result corresponds to an increased hypothalamic expression of POMCA1 and $P O M C B$ in rainbow trout after 4 months of feed deprivation [46]. In another experiment with rainbow trout, hypothalamic POMCA1 was down-regulated after 28 days of feed deprivation [50]. However, POMCA paralogues could not be distinguished in the present study, and a possible subfunctionalisation of these in the charr, which may be reflected in different responses to feed deprivation, cannot be excluded.

Putatively anorexigenic corticotrophin releasing factor $(C R F)$ expression was lower in FDP charr at $\mathrm{T}_{1}$ than at $\mathrm{T}_{0}$ (LogFC - 0.55). Previously, reduced CRF brain expression levels were observed in goldfish (Carassius auratus) after 7 days of feed deprivation [51] whereas no changes were observed after short (7 days)- and longterm (4 weeks) feed deprivation in charr [19] or after long-term feed deprivation in rainbow trout [46].

In rat, the preprotachykinin 1 (PPT) protein, encoded by the TAC1 gene, has been shown to be negatively regulated by ghrelin and high fat diets, and hence is assumed to be involved in regulating adiposity in rodents [52]. In goldfish, the post-prandial increase of hypothalamic expression of $\mu-P P T$ has led to the suggestion that $\mu$-PPT may signal satiety [53]. In the present study, brain TAC1 expression was lower expressed in FDP charr at $\mathrm{T}_{1}$ than at $\mathrm{T}_{0}(\log \mathrm{FC}-0.51)$.

The function of locally produced LEP in the brain is still a matter of debate, both in mammals and in fish [54-56], and results from other studies have so far not provided evidence for a role of central LEP in appetite regulation in fish $[18,56]$. This study revealed a higher LEP expression in both fed ( LogFC 1.7) and FDP fish (LogFC 1.3) at $\mathrm{T}_{1}$ compared with $\mathrm{T}_{0}$ fish. The lack of differences between fed and FDP charr at $\mathrm{T}_{1}$, despite a profound difference in condition factor (Fig. 1), may indicate that central leptin expression is not linked to adiposity. On the other hand, LEPA1 was found to be more highly expressed in the hypothalamus of hyperphagic charr in July than of anorexic charr in May and January [18].

Previous studies have shown a conserved orexigenic function of NPY in fish $[12,57,58]$. NPY expression was lower in fed fish at $\mathrm{T}_{1}$ compared to $\mathrm{T}_{0}$ ( $\left.\operatorname{LogFC}-0.55\right)$ while no difference was seen between FDP and $\mathrm{T}_{0}$. As such, based on the brain transcriptome, no hunger signalling by up-regulation of NPY could be found in the FDP fish. This finding is in accordance with the lack of responses seen in other feed deprivation studies with in Atlantic cod [49], Atlantic salmon [48], charr [19] and rainbow trout [46].

Apelin is considered another potent orexigenic actor in fish $[59,60]$. Our data did not reveal an effect of longterm feed deprivation on apelin expression. Brain expression of apelin receptor (APJA), was, however, higher in fed fish at $\mathrm{T}_{1}$ than in fed fish at $\mathrm{T}_{0}(\operatorname{LogFC}=0.99)$ but not different between FDP and fed fish at $\mathrm{T}_{0}$.

In summary, the results of the present study did not show expected responses to feed deprivation in the expression of candidate genes involved in appetite regulation in fish. This result does not necessarily contradict an appetite regulatory role of these actors in this fish. In a previous study with charr, no differences in the hypothalamic expression of $A g R P, M C 4 R, C R F, N P Y, C A R T$, $P O M C$ s and $L E P R$ were seen between fed and 4 weeks feed deprived fish, whereas the expression of, CART, $M C 4 R$ and $A g R P$ changed in feed deprived upon refeeding or exposure to feed flavour for 1 or $5 \mathrm{~h}$ [19]. This indicates that changes in gene expression are more likely to be seen during transition stages than during steadystate situations.

Such paradoxical results may be interpreted as an adaptation in high-latitude fish to save energy by reducing feed searching behaviour when feed is absent.

\section{Genes related to energy metabolism and seasonality}

Insulin-like growth factor 1 (IGF1) is key growth regulating hormone in vertebrates, and plasma levels of IGF1 usually correlate positively with growth in fish [61]. Accordingly, it has been shown that plasma IGF1 levels vary proportionally with increases and decreases in feeding rate in Arctic charr [62]. Furthermore, hypothalamic IGF1 expression was reduced by 1 month feed deprivation resulting in a positive correlation also between hypothalamic IGF1 expression and $K$ of fed and feed deprived fish [19]. In the present study, IGF1 expression was, as expected, downregulated in feed deprived charr at $\mathrm{T}_{1}$ compared to fed charr at $\mathrm{T}_{0}$. However, no difference was found in central IGF1 expression between fed and feed deprived charr at $T_{1}$, despite the huge difference in $K$ between feed deprived and fed charr at $\mathrm{T}_{1}$ (Fig. 1). This discrepancy in results between studies on Arctic charr may relate to the fact that hypothalamic IGF1 expression was measured in the former study by Striberny and Jørgensen [19], while whole brain IGF1 expression was measured in the present study. 
Dio2 converts thyroxin (T4) to the biologically active triiodothyronine (T3) which, in turn, is known as an enhancer of several biological processes and exerts pleiotropic functions in the mammalian brain [63]. In mammals and birds, the increase in day length in spring stimulates hypothalamic Dio2 expression, thereby stimulating a range of processes related to seasonal phenotype transitions, including appetite [64]. Similarly, it was recently shown that brain expression of the paralogue Dio2b was elevated in response to an increased day length in Atlantic salmon [65]. We found a significantly lower hypothalamic Dio $2 b$ expression at $\mathrm{T}_{1}$ than at $\mathrm{T}_{0}$ in both fed and FDP charr, and a lower expression in FDP charr than in fed charr at $\mathrm{T}_{1}(\operatorname{LogFC}=-1.19 /-0.81)$ (Fig. 5). Our findings may be interpreted as a general decline in Dio $2 b$ expression during late summer, a decline that may have been enhanced by feed deprivation. In support of the latter, in the seasonal Djungarian hamster (Phodopus sungorus), hypothalamic Dio2 expression was reduced in response to fasting induced torpor during summer [66]. Further experiments are needed to characterize the function of Dio2 in seasonal processes, including feeding behaviour, in the highly seasonal Arctic charr.

\section{Nerve growth factor inducible (VGF) - a novel candidate involved in the control of appetite and energy homeostasis in fish?}

Interestingly, we found brain VGF (non-acronymic, nerve growth factor inducible) to be up-regulated $(\operatorname{LogFC}=0.54)$ in FDP compared to fed charr at $\mathrm{T}_{1}$ (Fig. 6). To the best of our knowledge, VGF has not been linked to energy metabolism and appetite control in fish. In mammals, the $V G F$ gene encodes for a $68 \mathrm{kDa}$ protein precursor that is abundantly expressed in the brain, particularly in the hypothalamus. VGF cleaves into several smaller peptides that have been shown to be involved in a multitude of processes including nerve growth upon injury, seasonality, and food intake/energy metabolism [67]. Several studies in rodents have given evidence for a role of VGF in the control of energy metabolism [68$70]$ and food intake [71]. Targeted deletion of VGF produces a lean, small, and hyperactive mouse [69]. In mammals, the function of VGF is complex and not entirely understood. For example, $48 \mathrm{~h}$ feed deprivation in mice caused in one study an up-regulation of hypothalamic VGF expression [69], and down-regulation in another study [70]. In mice, VGF derived neuropeptide TLQP-21 increases energy expenditure without affecting expression of $P O M C / C A R T$ and $A g R P / N P Y$, suggesting that TLQP-21 exerts its effects downstream of MC4R signalling [72]. Furthermore, in Siberian hamster, ARC $V G F$ expression was induced by a decrease in photoperiod [73] and reduced by $\mathrm{T}_{3}$ [74], raising evidence that
$V G F$ is involved in the control of seasonal feeding in this species. We found Dio2b expression to be lower in FDP charr than in fed charr at $\mathrm{T}_{1}$. This indicates a reduced thyroid hormone action, which based on the results from Siberian hamster, could be underlying the increased VGF expression seen in feed deprived charr. The implication of this gene in both appetite regulation and seasonality in mammals makes it of particular interest in the strongly seasonal Arctic charr.

\section{Conclusion}

In conclusion, the general gene expression patterns in brain transcriptome of fed and feed deprived charr displayed strong shifts in expression of contigs involved in basic cell metabolic processes over time, and only minor differences were seen in response to feed deprivation. However, these changes during the charr's summer growth appeared to be enhanced by feed deprivation, indicated by a higher number of differentially expressed contigs over time in feed deprived than in fed charr. A decrease in the expression of haemoglobin subunits together with an increase in expression of genes involved in apoptosis, revealed from GO analysis, may indicate a negative effect of feed deprivation on brain metabolism. This is also supported by a substantially stronger reduction in Dio $2 b$ expression in feed deprived than in fed charr from start to end of the experiment. However, the brain is a heterogeneous tissue that consists of many different cell types, including neural and non-neural tissue; consequently, further studies are needed to get a better spatial resolution of where the observed changes occur.

Generally, a note of caution is expressed when measurements only include RNA abundances and not the corresponding protein levels. However, in a recent study in which a combined transcriptomic and proteomic approach were applied it was concluded that transcriptomic analyses indeed can be used to predict protein copy numbers [75]. Despite the marked divergence of body mass and $K$, no clear hunger signalling was found between fed and feed deprived charr, when searching the lists of differentially expressed contigs for anorexigenic and orexigenic candidate genes known to be involved in appetite regulation in fish. Hence, these results illustrate that even during summer the anadromous charr have a vast ability and flexibility to deal with food deprivation.

\section{Methods}

Ethics statement

Fish handling and euthanasia (see below) was performed by a competent person and in accordance with the European Union Regulations concerning the protection and welfare of experimental animals (European directive 91/ 492/CCE). The experiment was approved by the 
Norwegian Committee on Ethics in Animal Experimentation (ID 3630).

\section{Feed deprivation experiment and sampling of fish}

The charr used in the present study were two-year-old immature offspring of the anadromous Hammerfest strain, originating from wild charr caught in 1984 and since then bred at Tromsø Aquaculture Research Station, where the experiment was carried out. Until the start of the experiment they had been held on natural water temperature and light conditions (transparent roof) and fed a commercial Arctic charr feed (Skretting, Stavanger, Norway) ad libitum by automatic feeders. On June $25\left(\mathrm{~T}_{0}\right), 2014,42$ fish were anesthetized in Benzocaine $(60 \mathrm{ppm})$ and tattoo-tagged with Alcian Blue staining dye using a Pan Jet needleless injector (Wright Dental, Dundee, UK). Body mass and fork length were measured and the fish were distributed between two $300 \mathrm{~L}$ tanks supplied with fresh water. Another 12 fish were dip netted from the stock tank and euthanized by an overdose of Benzocaine (150 ppm). Body mass and fork length were measured. Subsequently, the fish were decapitated and the belly was cut open for sex determination. In order to rule out potential sex-specific differences, only male fish were sampled for RNA-seq. On a total of 5 fish, brains were dissected out and separated into telencephalon, mesencephalon and hypothalamus. Tissues were stored in $1.5 \mathrm{ml}$ Eppendorf tubes containing $1 \mathrm{ml}$ of RNAlater (ThermoFisher Scientific, MA, USA). Samples were kept at $4{ }^{\circ} \mathrm{C}$ for $24 \mathrm{~h}$, and then frozen at $-20^{\circ} \mathrm{C}$ until RNA extraction.

On the same day, 220 fish from the stock tank were distributed amongst the two tanks in which the tattooed fish had been placed (130 fish per tank). From then on, the fish in one tank were fed (Fed) with the same commercial feed as before. Fed fish were fed two main meals at $08.00 \mathrm{AM}$ and 3.00 PM by automatic feeders and in addition, between the main meals to ensure excess feed availability. The fish in the other tank were feed deprived (FDP) until the end of the experiment. All fish were held at simulated natural photoperiod $\left(69^{\circ} \mathrm{N}\right)$, which was 24 $\mathrm{h}$ light at that time of the year, and both experimental tanks were supplied with fresh water provided by a flowthrough system. Ambient natural water temperature was $4.5^{\circ} \mathrm{C}$ at the start and $13.5^{\circ} \mathrm{C}$ at the end of the experiment. On July $23\left(\mathrm{~T}_{1}\right), 12$ fish from each group were euthanized, from which 5 males were measured and sampled as described above. Finally, the tagged fish were anesthetized and measured for body mass and length.

The high number of fish in each treatment group compared to the number of fish sampled was justified by the need to avoid formation of social hierarchies in the fed group. The tagged fish were included in order to monitor the body mass and condition factor development of the fish in the two treatment groups. Fulton's condition factor $(K)$ was calculated according to Ricker (1975): $K=\left(\mathrm{W} \times \mathrm{L}^{-3}\right) \times 100$, where $\mathrm{W}$ is body mass in $\mathrm{g}$, and $\mathrm{L}$ is fork length in $\mathrm{cm}$.

\section{Sample preparation}

Tissues were disrupted using TissueLyser II (QIAGEN, Hilden, Germany), and RNA was extracted using the RNeasy Plus Universal Mini Kit (QIAGEN) according to the manufacturer's protocol. Concentration and purity of RNA were assessed using NanoDrop ND2000c (ThermoFisher Scientific, MA, USA) and when the 260/280 or $260 / 230$ absorbance ratio was below the quality threshold (1.8), samples were further purified using ethanol precipitation. Genomic DNA was removed by treating the RNA with Ambion TURBO DNA-free ${ }^{\mathrm{Tm}} \mathrm{Kit}$ (Life Technologies, CA, USA). In order to obtain a representative view of the main brain areas that have been shown to be involved in central appetite control, $3 \mu \mathrm{g}$ of RNA of each brain compartment (telencephalon, mesencephalon and hypothalamus) were pooled resulting in a total of $9 \mu \mathrm{g}$ RNA per brain and individual. Finally, the overall quality of RNA samples was assessed using Bio-rad Experion Bioanalyzer (Bio-rad, CA, USA) and the RQ ranged from 8.7-9.8 indicating high quality of all samples. We did not observe any clustering in MDS plot that would reflect any potential technical variation (Additional file 2: Figure S2). Samples were then shipped on dry-ice to the GenoToul sequencing platform, Toulouse, France for RNA-seq.

\section{CDNA library construction and paired-end RNA-seq}

RNA preparation and sequencing were performed at the GenoToul sequencing platform, Toulouse, France. Fifteen RNA libraries were prepared using the TruSeq RNA sample preparation Kit (Illumina, Hayward, CA, USA), involving the following steps. Poly-As containing mRNA were isolated from $3 \mu \mathrm{g}$ of total RNA. The mRNA was then chemically fragmented. The cleaved RNA fragments were reverse transcribed into first stranded cDNA using random primers, and second strand cDNA was then synthesized. Adaptors were ligated to the end-repaired cDNA, which contributed to fragment selection after the PCR enrichment step. Each library quality was validated measuring sample concentration and fragment size on an Agilent High Sensitivity DNA chip. Sequence hybridization to the flow cell and cluster generation was achieved using a cBot system and the cluster generation kit (Illumina, Hayward, USA). Hundred base pair fragments were sequenced in paired-end for the 15 samples. The samples were multiplexed and Sequenced By Synthesis (SBS) on an a single lane of the eight-lane flow cell of an Illumina HiSeq 2500 sequencer The sequencing lane of the flow cell was screened by a camera, driven by the HiSeq Control 
Software. Image correction and base calling was performed using the Real Time Analysis (RTA) software.

\section{General statistics, data assembly and annotation Testing for differences in body weight and $K$}

Data for weight and $K$ were not normally distributed and therefore, statistical testing was conducted on LOGtransformed data. Changes over time were tested using a repeated measures ANOVA. When differences were found, a pairwise comparison applying Bonferroni correction for multiple comparisons was used to determine main effects. Differences between treatment groups were tested using a 2-sample t-test. All statistical testing was done with SYSTAT 13 and figures were drawn using SigmaPlot 13 (both Systat Software, CA, USA). The significance level was set to $p<0.05$.

\section{Sequencing data}

RNA-Seq data assembly, annotation and quality assessment Read quality was checked within the ng6 environment [76] using fastQC [77] and BurrowsWheeler Aligner BWA [78] to search for contamination. The reads were assembled with the Drap pipeline (version 1.7) [79]. The individual sample assemblies were performed with runDrap using Oases with kmers 25, 31, $37,43,49,55,61,65,69$. The individual contig files filtered by FPKM (Fragments Per Kilobase per Million mapped reads) over one were then merged with runMeta and filtered again by FPKM over one to produce the reference contig set.

Contigs were annotated searching sequence homologies against the following Ensembl protein databases: blastx [80] Danio rerio, Gadus morhua, Oreochromis niloticus, Oryzias latipes, Takifugu rubripes, Tetraodon nigroviridis, Xiphophorus maculatus, refseq_rna blastn [81]; swissprot blastp [82]; unigene_Takifugu_rubripes.9 (blastn); unigene_Oryzias_latipes.30 (blastn); unigene_ Danio_rerio.126 (blastn); NCBI Arctic char ESTs (blastn); the contigs (blastn). Repeats were identified with repeatMasker [83] (version open-4-0-3, with standard parameters) using Repbase database [84]. The GO annotations were extracted from InterproScan [85] (May 2015 version) [86]. The best SwissProt, RefSeq, or Salmo salar NCBI ESTs hit result was used to classify species by best hits contribution.

Different approaches were used to verify the quality of the built contigs. First, the contigs were processed with BUSCO V2 [87] to verify the number of actinopterygii_ odb9 reference genes found and their reconstruction state (partial or complete). Then the Salmo salar protein sequences made available by the NCBI (GCF 000233375.1_ICSASG_v2_protein.faa) were aligned with BLAT (standard parameter, version 34) on the 6 frames translated contigs [88]. The alignment was filtered to retain only hits with at least $80 \%$ identity and $80 \%$ coverage giving the size of the set of well-reconstructed contigs. Finally, the assembly was validated by (1) verifying the realignment rate of the reads of each individual sample on the contigs, (2) mapping the reads of a charr gill transcriptome sequenced in 100 bp paired-end (SRA accession: SRX314607) [89] on the contigs. The Arctic charr genome [23] was released after we had completed our de novo transcriptome and related data analyses. Still, in order to further validate the data set, S. alpinus proteins and RNAs (NCBI ID: 12179) were aligned to the set of generated contigs using blat v. $35 \times 1$ with respectively $-\mathrm{t}=$ dnax $-\mathrm{q}=$ prot and standard parameters. The best blast hit was extracted in both cases. The alignments were filtered keeping only hits with at least $80 \%$ identity and $80 \%$ coverage.

Polymorphism: SNP and microsatellite search Reads were aligned to the contigs with bwa mem [78]. They were deduplicated with samtools rmdup, then GATK (Version 3.0-0-g6bad1c6) base quality score recalibration was applied [90]. Indel realignment, SNP and INDEL discovery were performed with HaplotypeCaller using standard hard filtering parameters according to GATK Best Practices recommendations [91, 92]. Indels and SNP were independently filtered; 3 per window of $18 \mathrm{~b}$ with a minimal quality of 30 . The micro-satellites discovery was conducted using Tandem Repeats Finder Version 4.04 [89] using the following parameters: 2, 7, 7, $80,10,50,500-\mathrm{f}-\mathrm{d}-\mathrm{m}^{2}$. These analyses will not be interpreted in the current study but were meant to be made accessible on our de novo transcriptome interface, see data mining interface section for URL and details.

\section{Differential expression of contigs}

Patterns of gene expression Data exploration and gene expression analyses were performed using various packages implemented in $\mathrm{R}$ version 3.3 .1 (2016-06-21). A sample correlation heatmap based on Pearson's coefficient of correlation was drawn with pheatmap. The number of reads counts per contig was retrieved and each sample normalized, accounting for compositional differences between the libraries (calcNormFactors function EdgeR).

Paired comparisons of treatments groups were performed in EdgeR package version 3.8.6 [93] according to the users' guide procedure. We identified differentially expressed contigs using a general linear model and a quasi-likelihood F-test, and correcting for false discovery rate (corrected Benjamini and Hochberg $p<0.05$ ). The following contrasts were made (1) Fed fish at $T_{1}$ with $T_{0}$ fish ( $T_{1}$ Fed versus $T_{0}$ ),feed deprived fish at $T_{1}$ with $T_{0}$ fish ( $\mathrm{T}_{1}$ FDP versus $\mathrm{T}_{0}$ ) and feed deprived charr at $\mathrm{T}_{1}$ 
versus fed charr at $T_{1}\left(T_{1}\right.$ FDP versus $T_{1 \_}$Fed $)$. Only contigs with a $\operatorname{logFC}$ greater than 0.5 and smaller -0.5 were kept for a further comparison using Venn diagrams and GO enrichment analyses. Up-set graphs [94] were drawn using UpsetR to visualize unshared and shared lists of up- and down-regulated contigs between all three comparisons (total of 6 lists). Chi-square tests were run to test whether there was a relationship of feeding regime and proportions of uniquely versus shared up- and downregulated contigs $(2 \times 2$ contingency tables $)$ of over-time-comparisons. Lists of up- and down-regulated contigs of the $T_{1 \_}$Fed versus $T_{0}$ and $T_{1}$ FDP versus $T_{0}$, comparisons were further compared in the JVenn interface [95] in order to identify (1) contigs that were differentially expressed only in fed charr, (2) contigs that were only differentially expressed in FDP charr and (3) contigs that differed over time regardless of diet, i.e. a seasonal effect independent of the feeding regime (the shared portion of the Venn diagram). Resulting Venn diagrams where drawn in Venn Diagram Plotter [96] (Additional file 1: Figure S1). All lists of differentially expressed genes generated from the initial EdgeR comparison (no $\log$ fold change cut-off) were searched for candidate genes known to be involved in appetite regulation and energy metabolism.

GO enrichment Gene ontology (GO) term enrichment was obtained using the TopGo package [97]. It consisted of the identification of terms that host more differentially expressed contigs than expected by chance in a specific comparison. Enrichment of terms by differentially expressed contigs was assessed using Fisher's exact test $(p<0.05)$. This analysis focused on Biological Processes. Only terms that were enriched by 3 or more contigs were presented in the results.

Each of the three gene lists generated by Venn diagrams (Additional file 1: Figure S1) were investigated for GO enrichment, and lists of up- and down-regulated contigs were analyzed separately. Finally, GO enrichment analysis was conducted with the lists of up- and down-regulated contigs of the endpoint comparison.

\section{Data mining interface}

The assembled contigs were annotated using the RNAseq de novo ngs-pipelines processing chain [98] and the results have been uploaded to a web-based user interface build upon biomart [99].

\section{Additional files}

Additional file 1: Figure S1. Venn diagrams comparing up- and downregulated contigs over time between the two treatments: $T_{1}$ Fed versus $T_{0}$ and $T_{1} \_F D P$ versus $T_{0}(F D R<0.05$. LogFC cut-off $0.5 /-0.5)$. Yellow: contigs uniquely differentially expressed in $T_{1}$ Fed versus $T_{0}$ comparison (input for GO enrichment Table 3 and Table 4, Additional file 3: Table S1, Additional file 4: Table S2), blue: contigs uniquely differentially expressed in $T_{1}$ FDP versus $T_{0}$ comparison (input for $\mathrm{GO}$ enrichment Table 7 and Table 8, Additional file 7: Table S5, Additional file 8: Table S6). White: contigs that were found to be differentially expressed over time regardless of feeding regime (input for GO enrichment Table 5 and Table 6, Additional file 5: Table S3, Additional file 6: Table S4). (JPG $67 \mathrm{~kb}$ )

Additional file 2: Figure S2. MDS Plot of the 15 samples. T0 1-5: T0 charr, T1 6-10: T1_Fed charr, T1 11-15: T1_FDP charr. (EPS 6 kb)

Additional file 3: Table S1. Biological processes enriched by upregulated contigs only found in Fed versus $T_{0}$ (see Venn diagram Additional file 1: Figure S1). Terms sorted by the number of contributing contigs. (DOCX $19 \mathrm{~kb}$ )

Additional file 4: Table S2. Biological processes enriched by downregulated contigs only found in Fed versus $T_{0}$ (see Venn diagram Additional file 1: Figure S1) Terms sorted by the number of contributing contigs. (DOCX $24 \mathrm{~kb}$ )

Additional file 5: Table S3. Biological processes enriched by upregulated contigs found in Fed versus $T_{0}$ and FDP versus $T_{0}$ (see Venn diagram Additional file 1: Figure S1). Terms sorted by the number of contributing contigs. (DOCX $28 \mathrm{~kb}$ )

Additional file 6: Table S4. Biological processes enriched by downregulated contigs found in Fed versus $T_{0}$ and FDP versus $T_{0}$ (see Venn diagram Additional file 1: Figure S1). Terms sorted by the number of contributing contigs. (DOCX $22 \mathrm{~kb}$ )

Additional file 7: Table S5. Biological processes enriched by upregulated contigs only found in FDP versus $T_{0}$ (see Venn diagram Additional file 1: Figure S1). Terms sorted by the number of contributing contigs. (DOCX $23 \mathrm{~kb}$ )

Additional file 8: Table S6. Biological processes enriched by downregulated contigs only found FDP versus $T_{0}$ (see Venn diagram Additional file 1: Figure S1). Terms sorted by the number of contributing contigs. (DOCX $25 \mathrm{~kb})$

Additional file 9: Table S7. Biological processes enriched by upregulated contigs comparing feed deprived versus fed charr at end of experiment. Terms sorted by the number of contributing contigs. (DOCX $22 \mathrm{~kb}$ )

Additional file 10: Table S8. Biological processes enriched by downregulated contigs comparing feed deprived versus fed charr at end of experiment. Terms sorted by the number of contributing contigs. (DOCX $21 \mathrm{~kb}$ )

Additional file 11: Table S9. FDP versus Fed Top annotated upregulated contigs. $\log F C=\log$ fold change, $\log C P M=\log$ counts per million, $F=F$ statistic, $F D R=$ false discovery rate. $(X L S X 10 \mathrm{~kb})$

Additional file 12: Table S10. FDP versus Fed Top annotated downregulated contigs. $\log F C=$ Log fold change, $\log C P M=\log$ counts per million, $F=F$ statistic, FDR = false discovery rate. (XLSX $11 \mathrm{~kb}$ )

Additional file 13: Table S11. $T_{1}$ Fed versus $T_{0}$ Top annotated upregulated contigs. $\log F C=\log$ fold change, $\log C P M=\log$ counts per million, $F=F$ statistic, FDR = false discovery rate. (XLSX $13 \mathrm{~kb}$ )

Additional file 14: Table S12. $T_{1}$ Fed versus $T_{0}$ Top annotated downregulated contigs. $\log F C=$ Log fold change, $\log C P M=\log$ counts per million, $F=F$ statistic, $F D R=$ false discovery rate. $(X L S X 12 \mathrm{~kb}$ )

Additional file 15: Table S13. $T_{1}$ FDP versus $T_{0}$ Top annotated upregulated contigs. $\log F C=\log$ fold change, $\log C P M=\log$ counts per million, $F=F$ statistic, $F D R=$ false discovery rate. (XLSX $12 \mathrm{~kb}$ )

Additional file 16: Table S14. $T_{1}$ FDP versus $T_{0}$ Top annotated downregulated contigs. $\log F C=\log$ fold change, $\log C P M=\log$ counts per million, $F=F$ statistic, $F D R=$ false discovery rate. $(X L S X 12 \mathrm{~kb}$ )

\section{Abbreviations}

AgRP: Agouti-related peptide; APJA: Apelin receptor; ARC: Arcuate nucleus; CART: Cocaine-and amphetamine regulated transcript; CRF: Corticotrophin releasing factor; DIO2: Deiodinase 2; FDP: Feed deprived; FDR: False discovery rate; FPKM: Fragments Per Kilobase Million; GO: Gene ontology; 
Hb: Haemoglobin; IGF1: Insulin-like growth factor 1; K: Fulton's condition factor; LEP: Leptin; LEPR: Leptin receptor; LogFC: Log fold change; MC4R: Melanocortin receptor 4; MCR: Melanocortin receptor; NPY: Neuropeptide Y; POMC: Proopiomelanocortin; PPT: Preprotachykinin; VGF: Nerve growth factor inducible; a-MSH: a-melanocyte-stimulating hormone

\section{Acknowledgements}

We thank the staff at Troms $\varnothing$ Aquaculture Research Station for taking care of the fish. Further, we like to thank Olivier Bouchez and his team at Genome \& Transcriptome GeT Genotoul for sequencing of the samples. Last but not least, we thank Hélène Volkoff for reading and commenting on the manuscript prior to submission and two reviewers for constructive comments during the revision process.

\section{Authors' contributions}

AS designed and performed the experiment, collected samples, extracted RNA, analysed and interpreted morphometric and transcriptome data and drafted the manuscript. EHJ designed and performed the experiment, collected samples, interpreted the results and was a major contributor in writing the final manuscript. CK performed the bioinformatic analyses, provided guidance in statistical analyses of transcriptome data and interpretation of results. EM contributed to experimental design, managed the project, analysed and interpreted data and was a major contributor in writing the manuscript. All authors read and approved the final manuscript.

\section{Funding}

UiT - The Arctic University of Troms $\varnothing$ was the main funding body for the experiment and data collection. Joint data analysis and writing of the article by Norwegian and French partners was supported by the French Ministries of Europe and Foreign affairs (Ministère de l'Europe et des Affaires étrangères - MEAE) and of higher education, research and innovation (Ministère de I'Enseignement supérieur, de la Recherche et de l'Innovation - MESRI) and the The Aurora mobility programme - researcher exchange between Norway and France (IS-AUR). The publication charges for this article have been funded by a grant from the publication fund of UiT - The Arctic University of Norway.

\section{Availability of data and materials}

The raw RNA-seq data generated and analysed during the current study are available in the SRA database, https://www.ncbi.nlm.nih.gov/sra under accession number SRP151983. In addition, we specifically developed an interface for this transcriptome. The entire dataset can be browsed at the following URL: http://ngspipelines2.toulouse.inra.fr:9002/.

\section{Ethics approval and consent to participate}

Fish handling and euthanasia (see below) was performed by a competent person and in accordance with the European Union Regulations concerning the protection and welfare of experimental animals (European directive 91/ 492/CCE). The experiment was approved by the Norwegian Committee on Ethics in Animal Experimentation (ID 3630).

\section{Consent for publication}

Not applicable.

\section{Competing interests}

The authors declare that they have no competing interests.

\section{Author details}

'Department of Arctic and Marine Biology, UiT - The Arctic University of Norway, Tromsø, Norway. ${ }^{2}$ Plateforme Bioinformatique Toulouse, Midi-Pyrénées UBIA, INRA, Auzeville Castanet-Tolosan, France. ${ }^{3}$ Sorbonne Université, CNRS, Biologie Intégrative des Organismes Marins, BIOM, F-66650 Banyuls-sur-Mer, France.

Received: 7 December 2018 Accepted: 31 May 2019 Published online: 27 June 2019

\section{References}

1. Wynne K, Stanley S, McGowan B, Bloom S. Appetite control. J Endocrinol. 2005;184(2):291-318.
2. Elmquist JK, Elias CF, Saper CB. From Lesions to Leptin: Hypothalamic Control of Food Intake and Body Weight. Neuron. 1999;22:221-32.

3. Schwartz MW, Woods SC, Porte D Jr, Seeley RJ, Baskin DG. Central nervous system control of food intake. Nature. 2000;404:661-71.

4. Cone RD, Cowley MA, Butler AA, Fan W, MD L, Low MJ. The Arcuate nuecleus as a conduit for diverse signals relevant to energy homeostasis. Int J Obes. 2001;25(5):63-7.

5. Cone RD. The Central Melanocortin System and Energy Homeostasis. Trends Endocrinol Metab. 1999;10(6):211-6.

6. Nijenhuis WA, Oosterom J, Adan RA. AgRP (83-132) acts as an inverse agonist on the human-melanocortin-4 receptor. Mol Endocrinol. 2001;15(1): 164-71.

7. Cerda-Reverter JM, Martinez-Rodriguez G, Zanuy S, Carrillo M, Larhammar D. Molecular evolution of the neuropeptide $Y$ (NPY) family of peptides: cloning of three NPY-related peptides from the sea bass (Dicentrarchus labrax). Regul Pept. 2000;95(1-3):25-34

8. Cortes R, Navarro S, Agulleiro MJ, Guillot R, Garcia-Herranz V, Sanchez E, Cerda-Reverter JM. Evolution of the melanocortin system. Gen Comp Endocrinol. 2014;209:3-10.

9. Volkoff H. The Neuroendocrine Regulation of Food Intake in Fish: A Review of Current Knowledge. Front Neurosci. 2016;10:1-31.

10. Volkoff H, Canosa LF, Unniappan S, Cerda-Reverter JM, Bernier NJ, Kelly SP, Peter RE. Neuropeptides and the control of food intake in fish. Gen Comp Endocrinol. 2005;142(1-2):3-19.

11. Hoskins $L J$, Volkoff $H$. The comparative endocrinology of feeding in fish: insights and challenges. Gen Comp Endocrinol. 2012;176(3):327-35.

12. Yokobori E, Azuma M, Nishiguchi R, Kang KS, Kamijo M, Uchiyama M, Matsuda K. Neuropeptide Y stimulates food intake in the Zebrafish, Danio rerio. J Neuroendocrinol. 2012;24(5):766-73.

13. Silverstein JT, Breininger J, Baskin DG, Plisetskaya EM. Neurpepeptide-Y like Gene Expression in the Salmon Brain Increases with Fasting. Gen Comp Endocrinol. 1998;110:157-65.

14. Babichuk NA, Volkoff $\mathrm{H}$. Changes in expression of appetite-regulating hormones in the cunner (Tautogolabrus adspersus) during short-term fasting and winter torpor. Physiol Behav. 2013;120:54-63.

15. Swanson HK, Kidd KA, Reist JD, Trudel M. Quantifying importance of marine prey in the diets of two partially anadromous fishes. Can J Fish Aquat Sci. 2011;68(11):2020-8.

16. Jørgensen EH, Johnsen HK. Rhythmic life of the Arctic charr: adaptations to life at the edge. Mar Genomics. 2014;14:71-81.

17. Tveiten $\mathrm{H}$, Johnsen $\mathrm{HK}$, Jobling $\mathrm{M}$. Influence of the maturity status on the annual cycles of feeding and growth in Arctic charr reared at constant temperature. J Fish Biol. 1996;48:910-24.

18. Striberny A, Ravuri CS, Jobling M, Jorgensen EH. Seasonal Differences in Relative Gene Expression of Putative Central Appetite Regulators in Arctic Charr (Salvelinus alpinus) Do Not Reflect Its Annual Feeding Cycle. PLoS ONE. 2015;10(9):e0138857.

19. Striberny A, Jørgensen EH. Feedback from Arctic charr: Feed flavour stimulation and re-feeding after feed deprivation stimulate genes encoding both orexigenic and anorexigenic neuropeptides. Gen Comp Endocrinol. 2017;246:71-80.

20. Magnanou E, Noirot C, Falcon J, Jorgensen EH. Sequencing and characterization of a multi-organ Arctic charr transcriptome: A toolbox for investigating polymorphism and seasonal life in a high Arctic fish. Mar Genomics. 2016:29:45-53.

21. Norman JD, Ferguson MM, Danzmann RG. Transcriptomics of salinity tolerance capacity in Arctic charr (Salvelinus alpinus): a comparison of gene expression profiles between divergent QTL genotypes. Physiol Genomics. 2014;46(4):123-37

22. Norman JD, Ferguson MM, Danzmann RG. An integrated transcriptomic and comparative genomic analysis of differential gene expression in Arctic charr (Salvelinus alpinus) following seawater exposure. J Exp Biol. 2014;217(Pt 22): 4029-42.

23. Christensen KA, Rondeau EB, Minkley DR, Leong JS, Nugent CM, Danzmann RG, Ferguson MM, Stadnik A, Devlin RH, Muzzerall R, et al. The Arctic charr (Salvelinus alpinus) genome and transcriptome assembly. PLoS ONE. 2018; 13(9):e0204076.

24. SRA Database. https://www.ncbi.n/m.nih.gov/sra.

25. Jørgensen EH, Johansen SJS, Jobling M. Seasonal patterns of growth, lipid deposition and lipid depletion in anadromous Arctic charr. J Fish Biol. 1997; $51: 312-26$. 
26. Davidson WS, Koop BF, Jones SJ, Iturra P, Vidal R, Maass A, Jonassen I, Lien $\mathrm{S}$, Omholt SW. Sequencing the genome of the Atlantic salmon (Salmo salar). Genome Biol. 2010;11:403.

27. Panicz R, Klopp C, Igielski R, Hofsoe P, Sadowski J, Coller JA. Tench (Tinca tinca) high-throughput transcriptomics reveal feed dependent gut profiles Aquaculture. 2017;479:200-7.

28. Theissinger K, Falckenhayn C, Blande D, Toljamo A, Gutekunst J, Makkonen J, Jussila J, Lyko F, Schrimpf A, Schulz R, et al. De Novo assembly and annotation of the freshwater crayfish Astacus astacus transcriptome. Mar Genom. 2016;28:7-10.

29. Guobrandsson J, Franzdottir SR, Kristjansson BK, Ahi EP, Maier VH, Kapralova $\mathrm{KH}$, Snorrason SS, Jonsson ZO, Palsson A. Differential gene expression during early development in recently evolved and sympatric Arctic charr morphs. Peerj. 2018;6.e4345

30. Richter F, Meurers BH, Zhu C, Medvedeva VP, Chesselet MF. Neurons express hemoglobin alpha- and beta-chains in rat and human brains. J Comp Neurol. 2009;515(5):538-47.

31. Schelshorn DW, Schneider A, Kuschinsky W, Weber D, Kruger C, Dittgen T, Burgers HF, Sabouri F, Gassler N, Bach A, et al. Expression of hemoglobin in rodent neurons. J Cereb Blood Flow Metab. 2009;29(3):585-95.

32. Jobling M. Influence of body weight and temperature on growth rates of Arctic charr, Salvelinus alpinus (L.). J Fish Biol. 1983;22:471-5.

33. Drew RE, Rodnick KJ, Settles M, Wacyk J, Churchill E, Powell MS, Hardy RW, Murdoch GK, Hill RA, Robison BD. Effect of starvation on transcriptomes of brain and liver in adult female zebrafish (Danio rerio). Physiol Genomics. 2008;35(3):283-95.

34. McCue MD. Starvation physiology: reviewing the different strategies animals use to survive a common challenge. Comp Biochem Physiol A Mol Integr Physiol. 2010;156(1):1-18.

35. Tidwell JH, Webster CD, Clark JA. Effects of feeding, starvation, and refeeding on the fatty acid composition of channel catfish, Ictalurus punctatus, tissues. Comp Biochem Physiol. 1992;103A(2):365-8.

36. Mizushima N, Yamamoto A, Matsui M, Yoshimori T, Ohsumi Y. In vivo analysis of autophagy in response to nutrient starvation using transgenic mice expressing a fluorescent autophagosome marker. Mol Biol Cell. 2004; 15(3):1101-11.

37. Alirezaei M, Kemball CC, Flynn CT, Wood MR, Whitton JL, Kiosses WB. Short-term fasting induces profound neuronal autophagy. Autophagy. 2014;6(6):702-10.

38. Soengas J, Strong E, Fuentes J, Veira J, Andrés M. Food deprivation and refeeding in Atlantic salmon, Salmo salar: effects on brain and liver carbohydrate and ketone bodies metabolism. Fish Physiol Biochem. 1996; 15(6):491-511.

39. Soengas JL, Strong EF, Andres MD. Glucose, lactate, and b-hydroxybutyrate utilization by rainbow trout brain: changes during food deprivation. Physiol Zool. 1998;71(3):285-93.

40. Martin SA, Douglas A, Houlihan DF, Secombes CJ. Starvation alters the liver transcriptome of the innate immune response in Atlantic salmon (Salmo salar). BMC Genomics. 2010;11(1):418.

41. Salem M, Silverstein J, Rexroad CE 3rd, Yao J. Effect of starvation on global gene expression and proteolysis in rainbow trout (Oncorhynchus mykiss). BMC Genomics. 2007;8:328.

42. Wang $X$, Kopinke D, Lin J, McPherson AD, Duncan RN, Otsuna H, Moro E, Hoshijima K, Grunwald DJ, Argenton F, et al. Wnt signaling regulates postembryonic hypothalamic progenitor differentiation. Dev Cell. 2012;23(3): 624-36.

43. Benzler J, Andrews ZB, Pracht C, Stohr S, Shepherd PR, Grattan DR, Tups A. Hypothalamic WNT signalling is impaired during obesity and reinstated by leptin treatment in male mice. Endocrinology. 2013;154(12):4737-45.

44. Boucsein A, Benzler J, Hempp C, Stohr S, Helfer G, Tups A. Photoperiodic and Diurnal Regulation of WNT Signaling in the Arcuate Nucleus of the Female Djungarian Hamster, Phodopus sungorus. Endocrinology. 2016;157(2):799-809.

45. Helfer G, Tups A. Hypothalamic Wnt Signalling and its Role in Energy Balance Regulation. J Neuroendocrinol. 2016;28(3):12368.

46. Jørgensen EH, Bernier NJ, Maule AG, Vijayan MM. Effect of long-term fasting and a subsequent meal on mRNA abundances of hypothalamic appetite regulators, central and peripheral leptin expression and plasma leptin levels in rainbow trout. Peptides. 2016;86:162-70.

47. Nishio S-I, Gibert Y, Berekelya L, Bernard L, Brunet F, Guillot E, Le Bail J-C, Sánchez JA, Galzin AM, Triqueneaux G. Fasting induces CART downregulation in the zebrafish nervous system in a cannabinoid receptor 1dependent manner. Mol Endocrinol. 2012;26(8):1316-26.
48. Murashita K, Kurokawa T, Ebbesson LO, Stefansson SO, Rønnestad I. Characterization, tissue distribution, and regulation of agouti-related protein (AgRP), cocaine- and amphetamine-regulated transcript (CART) and neuropeptide Y (NPY) in Atlantic salmon (Salmo salar). Gen Comp Endocrinol. 2009;162(2):160-71.

49. Kehoe AS, Volkoff H. Cloning and characterization of neuropeptide Y (NPY) and cocaine and amphetamine regulated transcript (CART) in Atlantic cod (Gadus morhua). Comp Biochem Physiol A Mol Integr Physiol. 2007;146(3):451-61.

50. Leder $\mathrm{EH}$, Silverstein JT. The pro-opiomelanocortin genes in rainbow trout (Oncorhynchus mykiss): duplications, splice variants, and differential expression. J Endocrinol. 2006;188(2):355-63.

51. Maruyama K, Miura T, Uchiyama M, Shioda S, Matsuda K. Relationship between anorexigenic action of pituitary adenylate cyclase-activating polypeptide (PACAP) and that of corticotropin-releasing hormone (CRH) in the goldfish, Carassius auratus. Peptides. 2006;27(7):1820-6.

52. Trivedi C, Shan X, Tung Y-CL, Kabra D, Holland J, Amburgy S, Heppner K, Kirchner H, Yeo GS, Perez-Tilve D. Tachykinin-1 in the central nervous system regulates adiposity in rodents. Endocrinology. 2015;156(5):1714-23.

53. Peyon $\mathrm{P}$, Saied $\mathrm{H}$, Lin X, Peter R. Preprotachykinin gene expression in goldfish brain: Sexual, seasonal, and postprandial variations. Peptides. 2000; 21(2):225-31.

54. Morash B, Li A, Murphy PR, Wilkinson M, Ur E. Leptin Gene Expression in the Brain and Pituitary Gland. Endocrinology. 1999;140(12):5995.

55. Rønnestad I, Nilsen TO, Murashita K, Angotzi AR, Gamst Moen AG, Stefansson SO, Kling P, Thrandur Björnsson B, Kurokawa T. Leptin and leptin receptor genes in Atlantic salmon: Cloning, phylogeny, tissue distribution and expression correlated to long-term feeding status. Gen Comp Endocrinol. 2010;168(1):55-70.

56. Tinoco AB, Nisembaum LG, de Pedro N, Delgado MJ, Isorna E. Leptin expression is rhythmic in brain and liver of goldfish (Carassius auratus). Role of feeding time. Gen Comp Endocrinol. 2014;204:239-47.

57. Narnaware $Y K$, Peyon $P$, Lin X, Peter RE. Regulation of food intake by neuropeptide $Y$ in goldfish. Am J Physiol Regul Integr Comp Physiol. 2000;279:1025-34.

58. Aldegunde $M$, Mancebo M. Effects of neuropeptide $Y$ on food intake and brain biogenic amines in the rainbow trout (Oncorhynchus mykiss). Peptides. 2006:27(4):719-27.

59. Volkoff H, Wyatt JL. Apelin in goldfish (Carassius auratus): cloning, distribution and role in appetite regulation. Peptides. 2009;30(8):1434-40.

60. Lin F, Wu H, Chen H, Xin Z, Yuan D, Wang T, Liu J, Gao Y, Zhang X, Zhou C. Molecular and physiological evidences for the role in appetite regulation of apelin and its receptor APJ in Ya-fish (Schizothorax prenanti). Mol Cell Endocrinol. 2014;396(1-2):46-57.

61. Beckman BR. Perspectives on concordant and discordant relations between insulin-like growth factor 1 (IGF1) and growth in fishes. Gen Comp Endocrinol. 2011;170(2):233-52.

62. Cameron C, Moccia R, Azevedo PA, Leatherland JF. Effect of diet and ration on the relationship between plasma GH and IGF-1 concentrations in Arctic charr, Salvelinus alpinus (L.). Aquac Res. 2007;38(8):877-86.

63. Bernal J. Action of thyroid hormone in brain. J Endocrinol Invest. 2002;25(3): 268-88.

64. Nakane Y, Yoshimura T. Universality and diversity in the signal transduction pathway that regulates seasonal reproduction in vertebrates. Front Neurosci. 2014;8:115.

65. Lorgen M, Casadei E, Król E, Douglas A, Birnie MJ, Ebbesson LO, Nilsen TO, Jordan WC, Jørgensen EH, Dardente $H$. Functional divergence of type 2 deiodinase paralogs in the Atlantic salmon. Curr Biol. 2015;25(7):936-41.

66. Bank JH, Cubuk C, Wilson D, Rijntjes E, Kemmling J, Markovsky H, Barrett P Herwig A. Gene expression analysis and microdialysis suggest hypothalamic triiodothyronine (T3) gates daily torpor in Djungarian hamsters (Phodopus sungorus). J Comp Physiol B. 2017;187(5-6):857-68.

67. Lewis JE, Brameld JM, Jethwa PH. Neuroendocrine role for VGF. Front Endocrinol. 2015:6:3

68. Hahm S, Fekete C, Mizuno TM, Windsor J, Yan H, Boozer CN, Lee C, Elmquist JK, Lechan RM, Mobbs CV. VGF is required for obesity induced by diet, gold thioglucose treatment, and agouti and is differentially regulated in proopiomelanocortin-and neuropeptide $Y$-containing arcuate neurons in response to fasting. J Neurosci. 2002;22(16):6929-38.

69. Hahm S, Mizuno TM, Wu TJ, Wisor JP, Priest CA, Kozak CA, Boozer CN, Peng B, McEvoy RC, Good P. Targeted deletion of the Vgf gene indicates that the encoded secretory peptide precursor plays a novel role in the regulation of energy balance. Neuron. 1999;23(3):537-48. 
70. Foglesong GD, Huang W, Liu X, Slater AM, Siu J, Yildiz V, Salton SR, Cao L. Role of hypothalamic VGF in energy balance and metabolic adaption to environmental enrichment in mice. Endocrinology. 2016;2016(1):34-46.

71. Jethwa PH, Warner A, Nilaweera KN, Brameld JM, Keyte JW, Carter WG Bolton N, Bruggraber M, Morgan PJ, Barrett P. VGF-derived peptide, TLQP21, regulates food intake and body weight in Siberian hamsters. Endocrinology. 2007;148(8):4044-55.

72. Bartolomucci A, La Corte G, Possenti R, Locatelli V, Rigamonti A, Torsello A, Bresciani E, Bulgarelli I, Rizzi R, Pavone F. TLQP-21, a VGF-derived peptide, increases energy expenditure and prevents the early phase of diet-induced obesity. Proc Nat Acad Sci. 2006;103(39):14584-9.

73. Barrett P, Ross AW, Balik A, Littlewood PA, Mercer JG, Moar KM, Sallmen T, Kaslin J, Panula P, Schuhler S. Photoperiodic regulation of histamine $\mathrm{H} 3$ receptor and VGF messenger ribonucleic acid in the arcuate nucleus of the Siberian hamster. Endocrinology. 2005;146(4):1930-9.

74. Lewis JE, Brameld JM, Hill P, Wilson D, Barrett P, Ebling FJ, Jethwa PH. Thyroid hormone and vitamin D regulate VGF expression and promoter activity. J Mol Endocrinol. 2016;56(2):123-34.

75. Edfors F, Danielsson F, Hallström BM, Käll L, Lundberg E, Pontén F, Forsström B, Uhlén M. Gene-specific correlation of RNA and protein levels in human cells and tissues. Mol Syst Biol. 2016;12(10):883.

76. Mariette J, Escudié F, Allias N, Salin G, Noirot C, Thomas S, Klopp C. NG6: Integrated next generation sequencing storage and processing environment. BMC Genomics. 2012;13(1):462.

77. Andrews S: FastQC A Quality Control tool for High Throughput Sequence Data. http://www.bioinformatics.babraham.ac.uk/projects/fastqc/, Accessed May 2015.

78. Li H, Durbin R. Fast and accurate short read alignment with BurrowsWheeler transform. Bioinformatics. 2009;25(14):1754-60.

79. Cabau C, Escudie F, Djari A, Guiguen Y, Bobe J, Klopp C. Compacting and correcting Trinity and Oases RNA - Seq de novo assemblies. Peerj. 2017;5.e2988

80. Blastx (search protein databases using a translated nucleotide query), release 79. https://blast.ncbi.nlm.nih.gov/Blast.cgi?LINK_LOC= blasthome\&PAGE TYPE=BlastSearch\&PROGRAM=blastx, Accessed May 2015.

81. blastn Nucleotide collection (nr/nt). https://blast.ncbi.n/m.nih.gov/Blast. cgi?LINK_LOC=blasthome\&PAGE_TYPE=BlastSearch\&PROGRAM=blastn, Accessed May 2015.

82. Blastp (protein-protein BLAST). https://blast.ncbi.nlm.nih.gov/Blast.cgi?PAGE= Proteins, Accessed May 2015

83. RepeatMasker. http://www.repeatmasker.org/, Accessed May 2015.

84. RepBase Database. https://www.girinst.org/repbase/, Accessed May 2015.

85. InterProScan. https://www.ebi.ac.uk/interpro/search/sequence-search, Accessed May 2015

86. Jones $\mathrm{P}$, Binns D, Chang HY, Fraser M, Li WZ, McAnulla C, McWilliam H, Maslen J, Mitchell A, Nuka G, et al. InterProScan 5: genome-scale protein function classification. Bioinformatics. 2014;30(9):1236-40.

87. Simao FA, Waterhouse RM, loannidis P, Kriventseva EV, Zdobnov EM BUSCO: assessing genome assembly and annotation completeness with single-copy orthologs. Bioinformatics. 2015:31(19):3210-2.

88. Kent WJ. BLAT - The BLAST-like alignment tool. Genome Res. 2002;12(4): 656-64

89. Benson G. Tandem repeats finder: a program to analyze DNA sequences. Nucleic Acids Res. 1999:27(2):573-80.

90. McKenna A, Hanna M, Banks E, Sivachenko A, Cibulskis K, Kernytsky A, Garimella K, Altshuler D, Gabriel S, Daly M, et al. The Genome Analysis Toolkit: A MapReduce framework for analyzing next-generation DNA sequencing data. Genome Res. 2010;20(9):1297-303.

91. DePristo MA, Banks E, Poplin R, Garimella KV, Maguire JR, Hartl C, Philippakis AA, del Angel G, Rivas MA, Hanna M, et al. A framework for variation discovery and genotyping using next-generation DNA sequencing data. Nat Genet. 2011;43(5):491.

92. Van der Auwera GA, Carneiro MO, Hartl C, Poplin R, Del Angel G, LevyMoonshine A, Jordan T, Shakir K, Roazen D, Thibault J, et al. From FastQ data to high confidence variant calls: the Genome Analysis Toolkit best practices pipeline. Curr Protoc Bioinformatics. 2013;43(1110):11.10.11-33.

93. Robinson MD, McCarthy DJ, Smyth GK. edgeR: a Bioconductor package for differential expression analysis of digital gene expression data. Bioinformatics. 2009;26(1):139-40.

94. Lex A, Gehlenborg N, Strobelt H, Vuillemot R, Pfister H. UpSet: Visualization of Intersecting Sets. IEEE Transactions on Visualization and Computer Graphics. 2014;20(12):1983-92.
95. Bardou P, Mariette J, Escudié F, Djemiel C, Klopp C. jvenn: an interactive Venn diagram viewer. BMC Bioinf. 2014;15(1):293.

96. Pacific Northwest National Laboratory W: Venn Diagram Plotter. https:// omics.pnl.gov/software/venn-diagram-plotter, Accessed Oct 2015.

97. Alexa A. Rahnenfuhrer J: topGO: enrichment analysis for gene ontology. $R$ package version. 2016; R package version 2.24.0

98. NGS pipeline. https://forgemia.inra.fr/genotoul-bioinfo/ngspipelines.

99. Biomart. http://www.biomart.org/.

\section{Publisher's Note}

Springer Nature remains neutral with regard to jurisdictional claims in published maps and institutional affiliations.
Ready to submit your research? Choose BMC and benefit from:

- fast, convenient online submission

- thorough peer review by experienced researchers in your field

- rapid publication on acceptance

- support for research data, including large and complex data types

- gold Open Access which fosters wider collaboration and increased citations

- maximum visibility for your research: over $100 \mathrm{M}$ website views per year

At $\mathrm{BMC}$, research is always in progress.

Learn more biomedcentral.com/submissions 